Discussion Papers of the

Max Planck Institute for

Research on Collective Goods

2020/7

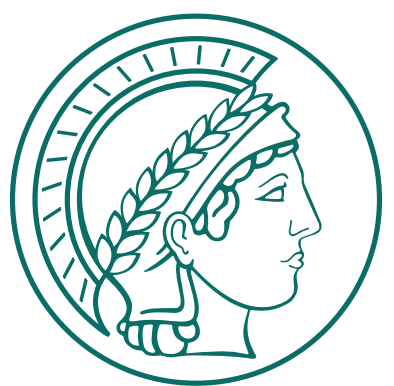

Dynamic Inefficiency and Fiscal Interventions in an Economy with Land and Transaction Costs

Martin F. Hellwig 


\title{
Dynamic Ineffiency and Fiscal Interventions in an Economy with Land and Transaction Costs
}

\author{
Martin F. Hellwig
}

March 2020

revised May 17, 2021 


\title{
Dynamic Inefficiency and Fiscal Interventions in an Economy with Land and Transaction Costs*
}

\author{
Martin F. Hellwig \\ Max Planck Institute for Research on Collective Goods \\ Kurt-Schumacher-Str. 10 \\ D - 53113 Bonn, Germany
}

May 17, 2021

\begin{abstract}
In the discussion whether real interest rates smaller than real growth rates can be taken as evidence of dynamic inefficiency that calls for fiscal interventions, a seemingly killing objection points to land, a non-produced durable asset in positive supply, as a reason why dynamic inefficiency can be ruled out. If real interest rates were expected to be below real growth rates forever, the value of land would be unbounded, which is incompatible with equilibrium. The paper shows that this objection is not robust to the presence of an arbitrarily small per-unit-of-value transaction cost. The paper also specifies fiscal interventions that provide for Pareto improvements even though they involve a resource cost. For the debate about public debt policy, the land argument is a red herring because it is incompatible with the presence of fiat money and debt denominated in units of fiat money.

Key Words: Dynamic inefficiency, fiscal policy, public debt, overlappinggenerations models with land, transaction costs, pay-as-you-go retirement provision.
\end{abstract}

JEL: D15, D61, E21, E62, H63.

\section{Introduction}

The experience of low rates of interest over the past decade has revived the notion that, in an economy with an unbounded sequence of overlapping generations, laissez-faire allocations might be dynamically inefficient and that appropriate government intervention might induce a Pareto improvement. The

*Without implicating them, I thank Peter Diamond, Christoph Engel, Christian Hellwig, Hans-Jürgen Hellwig, Christian von Weizsäcker, and two referees for very helpful advice. 
argument goes back to Allais (1947, Appendix 2), ${ }^{1}$ Samuelson (1958), and Diamond (1965). Blanchard (2019) has provided it with a new impetus. Based on a thorough survey of theory and empirical developments, he suggests that a constellation with real interest rates smaller than real growth rates is likely to persist for some time. Therefore he suggests that public borrowing is cheap, in terms of budgetary effects and welfare effects and that a more active fiscal policy is called for. ${ }^{2}$

Even before Blanchard, von Weizsäcker $(2010,2014)$ had articulated similar views and triggered a lively debate among German economists. In this debate, Homburg (2014a) argued that dynamic inefficiency of laissez-faire allocations cannot arise if there is a non-produced, durable asset, such as land, that can serve as a store of value. This claim has figured prominently in the German economists' debate. Recently, Sinn (2020) used it to reject the relevance of the arguments of von Weizsäcker and Krämer (2019) for public debt policy.

In models exhibiting dynamic inefficiency, the underlying real structure, as given by preferences, endowments, and technologies, provides scope for indirect exchange between generations, with goods deliveries from generation t to generation $t-1$, from generation $t+1$ to generation $t$, which can only be exploited if there is a store of value that can serve as a medium of exchange between generations, with generation $\mathrm{t}$ acquiring it from generation $\mathrm{t}-1$ and reselling it to generation $t+1$. If this need for a store of value requires asset holdings at levels where real rates of return are lower than real growth rates, laissez-faire allocations are not Pareto efficient (Diamond 1965, Tirole 1985).

According to Homburg (2014 a), however, this phenomenon cannot arise in an economy with land because no matter how large the need for a store of value might be this need can always be met by having a sufficiently high price of land. If the demand for a store of value were very large, the equilibrium real interest rate in the economy might be close to the real growth rate, inducing the equilibrium land price to be very large, but the equilibrium real interest rate could not be below the real growth rate for an arbitrarily length of time. The theoretical argument had previously been made by von Mises (1924/1953, Part 3, Ch. V, §3), Allais (1947, Appendix 2), Homburg (1991) and Rhee (1991). ${ }^{3}$

On the face of it, this argument seems to kill any debate about dynamicinefficiency considerations as a basis for policy advice. Since land is obviously an important part of wealth, the argument suggests that there is no point in even discussing whether experience supports the proposition that we might be in a dynamically inefficient equilibrium. Blanchard and von Weizsäcker may well be right about the past, the present and the near future, but the theoretical argument seems to tell us that this constellation cannot last. An active fiscal

\footnotetext{
${ }^{1} \mathrm{I}$ am grateful to Peter Diamond for this reference. A very brief summary is given by Malinvaud (1987).

${ }^{2}$ Summers (2014) and Rachel and Summers (2019) also make important contributions to this discussion. They focus on the empirics and their implications for macroeconomic stabilization rather than welfare.

${ }^{3}$ Rhee (1991) actually argues that this point is moot if population growth or technical change cause the income share of the asset in question to become small over time.
} 
policy now might therefore have dangerous consequences in the future.

One can disdain this objection on the grounds that "the future" may be far away. However, the accusation that proposed policies have costs later can be effective in debate even if "later" is far in the future.

I therefore want to point out that the theoretical argument itself is nonrobust. For suppose that transactions involving land are costly and that the cost of a transaction is proportional to its value. Then, no matter how small the per-unit-of-value transaction cost may be, no general statement about the scope for dynamic inefficiency of laissez-faire allocations can be made. The reason is that, if the price of land is high, so is the transaction cost per unit of land. If the price of land is sufficiently high, the transaction cost will actually exceed the value of the produce (or other benefit) from the land and the real rate of return on land, net of the transaction cost, will be negative. Any equilibrium allocation with this property exhibits dynamic inefficiency, i.e. there is some scope for a Pareto improvement. ${ }^{4}$

Can such an improvement be implemented by fiscal interventions? The answer to this question depends on the costs associated with the intervention. In the overlapping-generations model, a simple intervention involving a lump sum tax on people in the first period and a lump sum transfer to people in the second period of their lives in fact will always improve on the laissez-faire allocation if, in relative terms, the associated dissipation of resources, i.e. the amount by which the transfer falls short of the tax is smaller than the excess of the per-unit transaction cost over the real rate of return on land, i.e. the amount by which the net rate of return on land is negative. If the fiscal intervention involves no dissipation of resources, it can provide a Pareto improvement whenever the laissez-faire outcome is dynamically inefficient. If the fiscal intervention involves some dissipation of resources, dynamic inefficiency as such is not sufficient for fiscal intervention to provide a Pareto improvement, but if the dissipation of resources through the fiscal intervention is relatively smaller than the transaction cost for land and the need for a store of value is sufficiently large, such an intervention will improve on the laissez-faire outcome.

From the perspective of the participants, a combined tax-and-transfer system provides a substitute for a store of value. The tax part of the system can be interpreted as an (involuntary) "investment", the transfer part as a "return" on this "investment". If the "rate of return" on this investment exceeds the rate of return on land, participants benefit because the fiscal intervention reduces the costs of storing value from one period to the next. With lump sum taxes and transfers, the fiscal intervention also causes the demand function for land to shift down, so there is an additional benefit because the equilibrium price of land goes down and the real rate of return on land goes up.

With "distortionary" interventions, when first-period tax payments and secondperiod transfer payments depend on the choices people make, one must also take

\footnotetext{
${ }^{4}$ An anonymous referee considers this point to be trivial, not worth a formal analysis. Its being trivial has not prevented Sinn (2020) from getting it wrong or Homburg (2014 a, b) from getting its cousin wrong, concerning the impact of a tax on land in an overlapping-generations model. On the latter point, see the next footnote.
} 
account of substitution effects. For a very simple model, I will show that the welfare assessment of such an intervention is the same as with lump sum taxes and transfers: If the implicit rate of return in the tax-and-transfer system exceeds the rate of return on land, an increase in the tax rate raises welfare. In contrast to the lump sum case, however, here, I cannot generally sign the effect of the intervention on the land price and the rate of return on land. If utility functions exhibit elasticities of marginal utility that are greater than one, the substitution effects of changes in intertemporal relative prices dominate the income effects, so that, in response to an increase in the real rate of return from one period to the next, people will raise their demand for a store of value. I am unable to rule out the possibility that this effect has a positive effect on the price of land and a negative effect on the rate of return on land. However, this negative effect on the rate of return on land cannot outweigh the direct positive effect from the higher tax rate.

Much of the debate on incentive effects of pay-as-you-go systems for retirement provision has concentrated on negative incentive effects of payroll taxes on labour provision and production. If transfer payments under such a system depend on previous tax payments, one must also consider the incentive effects of the transfers. ${ }^{5}$ If the rate of return that is implicit in the tax-and-transfer system dominates the rate of return on private investments, the incentive effects of the transfer scheme on labour provision and production dominate the incentive effects of the tax scheme. These incentive effects may still be negative, i.e. labour provision and production may go down when the tax-and-transfer rate goes up, but if they do, the reason is an income effect from more advantageous terms of intertemporal trade rather than the substitution effect that is emphasized e.g. by Homburg (1990).

The arguments in this paper are closely related to arguments that Kim and Lee (1997) used to show that property taxes on land can induce dynamic inefficiency. ${ }^{6}$ However, the nature of the inefficiency is different and so is the policy intervention that it may call for. In this paper, as in Diamond (1965), dynamic inefficiency involves a failure of the first welfare theorem, i.e. the proposition that laissez-faire allocations are Pareto efficient. Removal of the inefficiency requires an active intervention by fiscal policy. In contrast, in Kim and Lee (1997), the dynamic inefficiency cannot be interpreted as a feature of laissez-faire allocations but must be seen as an instance of distortions caused by taxation. ${ }^{7}$

In the following, Section 2 presents the basic model. Section 3 provides a

\footnotetext{
${ }^{5}$ See the reaction of Breyer and Straub (1993) to Homburg (1990).

${ }^{6}$ Homburg (2014 b) disputes the claims of Kim and Lee (1997), arguing that dynamic inefficiency can only arise if the tax is confiscatory, in which case there would be no market for land; see also Homburg (2014 a). In Hellwig (2020), I use the methods developed in this paper to show that, whereas the first part of Homburg's claim is correct, the second part is not. The confiscation of land rents by taxation does not preclude the viability of a market in which land has a positive price because people want to use it as a store of value even though the net rate of return on land is negative.

${ }^{7}$ Remarkably, this distortion arises even though the supply of the object that is taxed is completely inelastic. On this point, see Feldstein (1977).
} 
characterization of stationary equilibria and shows that, laissez-faire allocations are Pareto-dominated if the demand for a store of value is sufficiently large. Section 4 shows how fiscal policy can be used to implement Pareto improvements over laissez-faire allocations whenever the resource dissipation associated with a fiscal intervention is small relative to the transaction cost on land. Section 5 discusses the relevance of the theoretical analysis for the policy discussion about public debt. Proofs of propositions are given in the appendix.

\section{The Basic Model}

The following simple model will serve to formalize the argument. There is an infinite sequence of periods $t=1,2, \ldots$ In each period, there is a single consumption good; this consumption good is non-storable. There is also land, a non-produced asset, a unit of which provides $a$ units of the consumption good in each period. For simplicity, I do not allow for real capital. ${ }^{8}$

In each period, a new generation of people is born. The population is assumed to be constant, so the size $N_{t}$ of the generation born in period $t$ is given as $N_{t}=N$ for all $t$.

A person born in period $t$ lives for two periods and is interested in the consumption good in periods $t$ and $t+1$. The person's preferences are given by the utility function $u\left(c_{1}^{t}\right)+v\left(c_{2}^{t}\right)$, where $c_{1}^{t}$ is consumption in the first period and $c_{2}^{t}$ is consumption in the second period of the person's life, and $u(\cdot), v(\cdot)$ are twice continuously differentiable, strictly increasing, and strictly concave functions, with $u^{\prime \prime}(c)<0$ and $v^{\prime \prime}(c)<0$ for all $c$, and moreover $\lim _{c \rightarrow 0} u^{\prime}(c)=$ $\lim _{c \rightarrow 0} v^{\prime}(c)=\infty$.

A person born in period $t$ has an initial endowment $\left(e_{1}^{t}, e_{2}^{t}\right)=(E, 0)$ of the consumption good in periods $t$ and $t+1$, where $E>0$, and no initial endowment of land. In period 1, there is also an old generation of size $N$. Each member of this generation has an endowment $L^{0}>0$ of land and gets utility $v\left(c_{2}^{0}\right)$ from consuming $c_{2}^{0}$.

In each period $t$, there is a market in which land can be traded against the consumption good of that period. The price per unit that a buyer has to pay is $p_{t}$, the price that the seller receives is $p_{t}(1-\pi) \in(0, p)$. The wedge $p_{t} \pi$ between the buyer's price and the seller's price is a transaction cost.

Given the land prices $p_{t}, p_{t+1}$ in periods $t$ and $t+1$, a person born in period $t$ chooses a consumption plan $\left(c_{1}^{t}, c_{2}^{t}\right)$ and a land purchase $L^{t}$ in period $t$ so as to maximize the utility

$$
u\left(c_{1}^{t}\right)+v\left(c_{2}^{t}\right)
$$

subject to the budget constraints

$$
c_{1}^{t}=E-p_{t} L^{t} \text { and } c_{2}^{t}=\left(a+p_{t+1}(1-\pi)\right) L^{t} .
$$

${ }^{8}$ With real capital, the arguments are more involved but otherwise unchanged, see for example Hellwig (2020). 
Members of the old generation in period 1 receive the harvest $a L^{0}$ on their land, sell their land at the price $p_{1}$, and consume the amount $\left(a+p_{1}(1-\pi)\right) L^{0}$ that is available net of the transaction cost.

An equilibrium is given by a land price sequence $\left\{p_{t}\right\}_{t=1}^{\infty}$ and an allocation $\left\{c_{2}^{t-1}, c_{1}^{t}, L^{t}\right\}_{t=1}^{\infty}$ such that (i) $c_{2}^{0}=\left(a+p_{1}(1-\pi)\right) L^{0}$ and, for $t=1,2, \ldots$, the triple $\left(c_{1}^{t}, c_{2}^{t}, L^{t}\right)$ maximizes the utility (2.1) under the constraints (2.2), and moreover (ii) for $t=1,2, \ldots$, the allocation $\left\{c_{2}^{t-1,} c_{1}^{t}, L^{t}\right\}_{\infty}^{t=1}$ satisfies

$$
N\left(c_{2}^{t-1}+c_{1}^{t}\right)=N\left(E+\left(a-\pi p_{t}\right) L^{t-1}\right)
$$

and

$$
N L^{t}=N L^{t-1} .
$$

The equilibrium is said to be stationary, if the land price $p_{t}$ is the same for all $t$. By the strict concavity of $u$ and $v$, in this case, the triple $\left(c_{1}^{t}, c_{2}^{t}, L^{t}\right)$ that maximizes (2.1) under the constraints (2.2) is also the same for all $t$.

\section{The Scope for Dynamic Inefficiency of Sta- tionary Equilibria under Laissez-Faire}

Proposition 3.1 For any $E, a, \pi, L^{0}$, there exists a unique stationary equilibrium. The stationary-equilibrium land price $p^{*}\left(E, a, \pi, L^{0}\right)$ is increasing in $E$, with

$$
\lim _{E \rightarrow \infty} p^{*}\left(E, a, \pi, L^{0}\right)=\infty
$$

To understand this proposition, it is useful to consider the maximization problem of generation $t \geq 1$ when the land price $p_{t}$ is the same for all $t$. In this case, the budget constraints (2.2) simplify to

$$
c_{1}^{t}=E-p L^{t} \text { and } c_{2}^{t}=(a+p(1-\pi)) L^{t},
$$

or, simpler yet,

$$
c_{1}^{t}+\frac{1}{r(p)} c_{2}^{t}=E,
$$

where

$$
r(p):=1+\frac{a}{p}-\pi
$$

is the gross real rate of return to holding land.

The solution to the problem of maximizing (2.1) subject to (3.3) is obviously the same for all generations $t \geq 1$. At this solution, the intertemporal marginal rate of substitution in consumption must equal $r(p)$, i.e., one must have

$$
\frac{u^{\prime}\left(c_{1}^{t}\right)}{v^{\prime}\left(c_{2}^{t}\right)}=r(p)
$$


Thus, in the present model, $r(p)$ is the relevant intertemporal relative price, analogous to the gross real rate of interest in other models.

Upon using (3.3) to substitute for $c_{1}^{t}$, one can rewrite (3.5) in the form

$$
\frac{u^{\prime}\left(E-\frac{1}{r(p)} c_{2}^{t}\right)}{\left.v^{\prime}\left(c_{2}^{t}\right)\right)}=r(p) .
$$

The left-hand side of (3.6) is increasing in $c_{2}^{t}$. For given $r(p)$, therefore, equations (3.5) and (3.3) determine a unique utility-maximizing plan for generation $t$, with second-period consumption given by (3.6). This plan determines the amount $E-c_{1}^{t}=\frac{1}{r(p)} c_{2}^{t}$ that a member of this generation wants to invest in land as a store of value. In equilibrium, this amount is just equal to the value $p L^{0}$ of the available land at the given price $p$. This condition holds for only one value of $p$. Lower (higher) values of $p$ would go along with higher (lower) rates of return $r(p)$ on land and therefore higher (lower) values for the desired investment $E-c_{1}^{t}$ in land as a store of value.

From Proposition 3.1, one immediately obtains the following result about the comparison between the equilibrium interest rate and the growth rate of the economy (which is zero).

Proposition 3.2 (a) If $\pi=0$, the net rate of return

$$
r\left(p^{*}\left(E, a, \pi, L^{0}\right)\right)-1=\frac{a}{p^{*}\left(E, a, \pi, L^{0}\right)}-\pi
$$

on land in the stationary equilibrium of Proposition 3.1 is positive. (b) If $\pi>$ 0 and $E$ is very large, the net rate of return on land (3.7) in the stationary equilibrium of Proposition 3.1 is negative.

Statement (a) is the result of Homburg (1991) and Rhee (1991), namely, in a model with zero growth, in the absence of transactions costs, the existence of land as non-produced durable asset ensures that the equilibrium net rate of interest must be positive. Statement (b) shows that the finding of statement (a) is non-robust. If $\pi$ is positive, no matter how close to zero, there exist parameter specifications for which the stationary-equilibrium demand for a store of value is so large and therefore the price of land is so large that the transaction cost outweighs the harvest, and the equilibrium rate of interest is negative. This is the case, in particular, if the endowment $E$ in the first period of life is very large, so participants want to shift a lot of purchasing power to the second period of life.

For a welfare assessment, I use a very weak concept of efficiency that focuses only on consumption and ignores the possibility of saving on transaction costs for land. An allocation $\left\{c_{2}^{t-1}, c_{1}^{t}\right\}_{t=1}^{\infty}$ of consumption levels in all periods is said to be weakly efficient if there is no alternative allocation $\left\{\hat{c}_{2}^{t-1}, \hat{c}_{1}^{t}\right\}_{t=1}^{\infty}$ of consumption levels that is Pareto preferred to $\left\{c_{2}^{t-1}, c_{1}^{t}\right\}_{t=1}^{\infty}$ and satisfies

$$
N\left(\hat{c}_{2}^{t-1}+\hat{c}_{1}^{t}\right) \leq N\left(c_{2}^{t-1}+c_{1}^{t}\right)
$$


for all $t$. Condition (3.8) ensures that the alternative allocation $\left\{\hat{c}_{2}^{t-1}, \hat{c}_{1}^{t}\right\}_{t=1}^{\infty}$ is feasible as it requires no more resources than are available for the allocation $\left\{c_{2}^{t-1}, c_{1}^{t}\right\}_{t=1}^{\infty}$.

Proposition 3.3 (a) If $r\left(p^{*}\left(E, a, \pi, L^{0}\right)\right)-1>0$, the allocation $\left\{c_{2}^{t-1}, c_{1}^{t}\right\}_{t=1}^{\infty}$ of consumption levels associated with the stationary equilibrium of Proposition 3.1 is weakly efficient. ${ }^{9}$

(b) If $r\left(p^{*}\left(E, a, \pi, L^{0}\right)\right)-1<0$, the allocation $\left\{c_{2}^{t-1}, c_{1}^{t}\right\}_{t=1}^{\infty}$ of consumption levels associated with the stationary equilibrium of Proposition 3.1 is not weakly efficient.

Proposition 3.3 confirms standard findings about dynamic efficiency and inefficiency of laissez-faire allocations. In particular, in an economy with zero growth, such allocations are dynamically efficient when the equilibrium net real rate of return on land is positive and dynamically inefficient when the equilibrium net real rate of return on land is negative.

An anonymous referee has suggested that the ordering of quantifiers in these results is inappropriate. The analysis should take $E$ as fixed and allow for $a$ to be arbitrarily large. If, for fixed values of the other parameters, $a$ is taken to be sufficiently large, one would certainly find that stationary-equilibrium allocations are efficient. However, this is not the relevant result for the Weizsäcker-Homburg debate. In this debate, von Weizsäcker (2010, 2014) argued that, because of high savings, the demand for a store of value, in Germany and worldwide, is so large that equilibrium real rates of interest must be negative unless this demand is met by sufficiently large supplies of paper assets, such as government debt.

The theoretical counterargument based on Homburg (1991) asserts that, no matter how large the demand for a store of value may be, with $a L^{0}>0$, (in the notation of this paper), equilibrium net real rates of interest cannot be negative because, if they were, the equilibrium value of land that earns a positive real return per unit would have to be unbounded. In this debate, $a$ and $L^{0}$ are taken as given, and the question is whether a sufficiently large propensity to save and a sufficiently large demand for a store of value can cause equilibrium real rates of interest to be negative.

This is precisely the question to which Propositions $3.1-3.3$ give an answer. Within the given model, $E$, the endowment that people have in the first period of their lives, drives the demand for a store of value as agents try to transform some of their first-period riches into second period consumption. Propositions 3.1 3.3 show that, in this setting, the existence of a linear ad valorem transaction cost, no matter how small it may be in per-unit terms, is sufficient to defuse the theoretical objection to von Weizsäcker $(2010,2014)$ or von Weizsäcker and Krämer (2019).

In the discussion with Homburg, von Weizsäcker and Krämer (2019) also refer to confiscation risks attached to real estate. If "land" is taken to comprise

\footnotetext{
${ }^{9}$ The conclusion also holds if $\frac{a}{p^{*}\left(E, a, \pi, L^{0}\right)}-\pi=0$, but in this case, the proof is much more involved, see, e.g., Okuno and Zilcha (1980). In the interest of brevity, I omit this case.
} 
structures, one might also think of natural disasters destroying the structures. Modelling these concerns is messy because one must say something on how life goes on after the calamity has struck. However, it is worth noting that, even without transaction costs, with $\pi=0$, if the probability of suffering a total loss from confiscation or disaster is $q$, condition (3.5), the condition for the equilibrium real rate of return, takes the form ${ }^{10}$

$$
\frac{u^{\prime}\left(c_{1}^{t}\right)}{v^{\prime}\left(c_{2}^{t}\right)}=(1-q) \cdot \frac{a+p}{p}
$$

For $q>0$, no matter how small, the right-hand side of this equation is less than one if $p$ is sufficiently large. This observation suggests that an analogue of Proposition 3.1 also holds for models involving these kinds of frictions. The underlying logic is the same: The Homburg mechanism of relying on increases in the price of land to balance any demand for a store of value enhances the impact of frictions whose significance rises with the value of land. The frictions do not prevent the equilibrium value of land from being extraordinarily high if the demand for a store of value is extraordinarily high, but then the costs of frictions are also extraordinarily high.

\section{Pareto Improvements by Fiscal Interventions}

Whereas the Pareto improvement in Proposition 3.3 (b) involves a direct intervention in the allocation of consumption, this section shows that such an improvement can sometimes be achieved by fiscal policy instruments, without such a direct intervention. In the following, I first consider the implications of levying a lump sum tax $T$ on each person when this person is young and of providing a lump sum transfer $S$ to each person when this person is old, leaving all other features of the model unchanged. Subsequently, I will consider the case of "distortionary taxes and transfers, where $T$ and $S$ depend on behaviour, and the tax and transfer schedules affect behaviour.

With a stationary population, feasibility requires that $S \leq T$. If $S=T$, the intervention involves no dissipation of resources, if $S<T$, the difference $T-S$ goes to waste. I will write

$$
S=(1-\sigma) T,
$$

where $\sigma \in[0,1)$ is a parameter for resource dissipation in the intervention.

With a tax $T$ on each person when this person is young and a transfer $S=(1-\sigma) T$ to each person when this person is old the budget constraints in (2.2) take the form

$$
c_{1}^{t}=E-p_{t} L^{t}-T \text { and } c_{2}^{t}=\left(a+p_{t+1}(1-\pi)\right) L^{t}+(1-\sigma) T .
$$

\footnotetext{
${ }^{10}$ The term $c_{2}^{t}$ in (3.5) must be interpreted as second-period consumption contingent on the event that no confiscation and no disaster occurs.
} 
If prices are the same, $p_{t}=p$, for all $t$, these constraints can be consolidated in the form

$$
c_{1}^{t}+\frac{1}{r(p)} c_{2}^{t}=E-T+\frac{1-\sigma}{r(p)} \cdot T .
$$

The tax-and-transfer scheme affects behaviour through its effects on the constraint (4.3). There are two effects. A direct effect is due to the appearance of $T$ on the right-hand side of (4.3). An indirect effect is due to the fact that changes in $T$ are likely to affect the equilibrium land price $p$ and the equilibrium rate of return on land $r(p)$.

The direct effect of an increase in $T$ on a person's budget is positive if

$$
1-\sigma>r(p)
$$

i.e., if the implicit rate of return $1-\sigma$ that a person achieves by making the first-period payment $T$ and receiving the second-period payment $S=(1-\sigma) T$ is greater than the rate of return on land $r(p)$; the direct effect is negative if the reverse inequality holds, i.e., if the implicit rate of return $1-\sigma$ under tax-and-transfer scheme is smaller than the rate of return on land, i.e., if

$$
1-\sigma<r(p) .
$$

With $c_{2}^{t}>(1-\sigma) T$, the indirect effect of an increase in $T$ on a person's budget is positive if the change makes the land price go down and the rate of return on land go up.

\subsection{Lump Sum Taxes and Transfers}

If $T$ and $S=(1-\sigma) T$ are specified in a lump sum manner, a stationary equilibrium is given by a sequence $\left\{p_{t}\right\}_{t=1}^{\infty}$ of land prices, with a constant price $p_{t}=p$ for all $t$, and an allocation $\left\{c_{2}^{t-1}, c_{1}^{t}, L^{t}\right\}_{t=1}^{\infty}$ such that (i) $c_{2}^{0}=\left(a+p_{1}(1-\pi)\right) L^{0}+S$ and, for $t=1,2, \ldots$, the triple $\left(c_{1}^{t}, c_{2}^{t}, L^{t}\right)$ maximizes the utility $(2.1)$ under the constraints (4.2), and moreover (ii) for $t=1,2, \ldots$, the allocation $\left\{c_{2}^{t-1,} c_{1}^{t}, L^{t}\right\}_{\infty}^{t=1}$ satisfies the market-clearing conditions

$$
N\left(c_{2}^{t-1}+c_{1}^{t}\right)=N\left(E+\left(a-\pi p_{t}\right) L^{t-1}-T+S\right)
$$

and

$$
N L^{t}=N L^{t-1} \text {. }
$$

The equilibrium is again said to be stationary if the land price $p_{t}$ is the same for all $t$. As before, the associated plans $\left(c_{1}^{t}, c_{2}^{t}, L^{t}\right)$ that maximize (2.1) subject to (4.2) are also the same for all $t$.

Proposition 4.1 For any $T<E$ and $S \leq T$, and any $E, a, \pi, L^{0}$, there exists a unique stationary equilibrium. The stationary-equilibrium land price $p^{* *}\left(T, S, E, a, \pi, L^{0}\right)$ is increasing in $E$, as well as decreasing in $T$ and $S$, with

$$
\lim _{E \rightarrow \infty} p^{* *}\left(T, S, E, a, \pi, L^{0}\right)=\infty .
$$


The argument is the same as for Proposition 3.1, except that now equation (3.5) takes the form

$$
\frac{u^{\prime}\left(E-T-\frac{1}{r(p)}\left(c_{2}^{t}-S\right)\right)}{v^{\prime}\left(c_{2}^{t}\right)}=r(p) .
$$

An increase in $T$ reduces resources available to people in the first period of their lives and reduces a person's desire to transfer resources from the first to the second period of life. An increase in $S$ increases resources available to people in the second period of their lives and also reduces the desire to transfer resources from the first to the second period of life. For given $p$ and $r(p)$, both effects reduce the amounts that people want to invest in land. The equilibrium price of land must therefore be lower, and the equilibrium rate of return on land higher. The equilibrium value of second-period consumption is also higher.

Turning to the welfare effects of a simultaneous increase in $T$ and $S=(1-$ $\sigma) T$, the following result shows that, if the stationary equilibria under laissezfaire are dynamically inefficient and if $\sigma$ is sufficiently small, or, equivalently, $\sigma<\pi$ and $E$ is sufficiently large, a fiscal intervention with lump sum taxes and transfers will generate a Pareto superior allocation.

Proposition 4.2 Assume that $\sigma<\pi$. If $\frac{a}{p^{*}\left(E, a, \pi, L^{0}\right)}+\sigma<\pi$, then for some $T>0$, the allocation $\left\{c_{2}^{t-1}, c_{1}^{t}\right\}_{t=1}^{\infty}$ of consumption levels associated with the stationary equilibrium of Proposition 3.1 is Pareto dominated by the allocation $\left\{\hat{c}_{2}^{t-1}, \hat{c}_{1}^{t}\right\}_{t=1}^{\infty}$ of consumption levels associated with the stationary equilibrium of Proposition 4.1 for $T>0$ and $S=(1-\sigma) T$. More generally, for any $T$ and $S=(1-\sigma) T$, if

$$
\frac{a}{p^{* *}\left(T, S, E, a, \pi, L^{0}\right)}+\sigma<\pi,
$$

some increase in lump sum taxes and transfers induces a Pareto improvement in the stationary-equilibrium allocation.

As I discussed above, a first-period lump sum tax $T$ and second-period lump sum transfer $S=(1-\sigma) T$ have a direct effect and an indirect effect on the consolidated budget constraint (4.3). The direct effect of a coordinated increase in $T$ and $S=(1-\sigma) T$ widens the budget of people in generations $t \geq 1$ if $1-\sigma$, the implicit gross rate of return that a person obtains from paying $T$ in the first period and receiving $S$ in the second period, is greater than $r(p)$. This inequality is equivalent to the condition that

$$
1-\sigma>\frac{a}{p^{* *}\left(T, S, E, a, \pi, L^{0}\right)}+1-\pi=r\left(p^{* *}\left(T, S, E, a, \pi, L^{0}\right)\right),
$$

which is exactly (4.10).

As for the indirect effect, Proposition 4.1 implies that the increase in $T$ and $S=(1-\sigma) T$ causes the equilibrium land price to go down. The rate of return on land therefore goes up. For people in generations $t \geq 1$, this is beneficial 
because, with $c_{2}^{t}>(1-\sigma) T$, these people are net savers in the first period of their lives and benefit from the increase in the per-unit return on their saving.

Generation 0 , the old generation in $t=1$, also benefits because second-period consumption goes up.

Depending on the relation between $\sigma$ and $\pi$, three cases must be distinguished: First, if $\sigma=0$, the specified fiscal intervention provides a Pareto improvement over laissez-faire whenever laissez-faire induces negative interest rates. This is similar to Proposition 3.3 (b), except that now the indirect effect of the fiscal intervention lowering the land price provides for an additional improvement.

Second, if $\sigma \in(0, \pi)$, the condition $\sigma<\pi-\frac{a}{p}$ is not necessarily satisfied when laissez-faire induces negative interest rates. However, if the laissez-faire demand for storing value is large enough, i.e. if $E$ is high enough, the equilibrium land price will be high enough so that the condition $\sigma<\pi-\frac{a}{p}$ is satisfied, i.e. despite the dissipation cost, the specified fiscal intervention will be Pareto-improving.

Third, if $\sigma \geq \pi$, the specified fiscal intervention does not provide a Pareto improvement over laissez-faire. Because the dissipation cost is so high, in this case, the direct effect of the fiscal intervention on $V$ is necessarily negative. Moreover, in this case, even if $\sigma=\pi$, one can show that the direct effect necessarily outweighs the indirect effect.

In those cases where a fiscal intervention is beneficial, the optimal intervention will involve a tradeoff between the direct effect and the indirect effect. It will raise $T$ to a point where (4.10) is no longer satisfied, where the direct effect of an additional increase in $T$ is in fact harmful but the harm is balanced by the benefits from the indirect effect.

\section{2 "Distortionary" Taxes and Transfers}

I next consider the case of endogenous $T$ and $S .{ }^{11}$ To keep the analysis simple, I set

$$
T=\tau \cdot\left(E-c_{1}\right) \text { and } S=s \cdot T=(1-\sigma) \cdot \tau \cdot\left(E-c_{1}\right) .
$$

If we reinterpret $c_{1}$ as leisure and $E-c_{1}$ as labour, both measured in units of output equivalents, then $T=\tau \cdot\left(E-c_{1}\right)$ is a tax on labour, imposed in the first

\footnotetext{
${ }^{11}$ This section was introduced in response to an anonymous referee's objecting to the preceding analysis on the grounds that "the government does not possess lump sum taxes as instruments, but can only tax economic activities, and any tax carries a deadweight loss". The referee's objection parallels Homburg's (1990) response to Breyer's (1989) showing that Homburg's (1987) treatment of the respective merits of unfunded (pay-as-you-go) and funded systems for retirement provision was false. Without giving the issue of funding further consideration, Homburg (1990) argued that, because of adverse incentive effects on labour inputs and production, a pay-as-you-go system with payroll taxes is always dominated by a system with lower payroll taxes and government debt that is forever rolled over. In response to Homburg (1990), Breyer and Straub (1993) observed that the negative incentive effects of payroll taxes disappear if benefits depend on contributions in an actuarially fair way. The specification here follows Breyer and Straub (1993), except that resource dissipation causes a deviation from actuarial fairness.
} 
period of a person's life, and $S=(1-\sigma) \cdot \tau \cdot\left(E-c_{1}\right)$ is a second-period transfer that is proportional to the first-period tax $\tau \cdot\left(E-c_{1}\right) .{ }^{12}$

With taxes and transfers specified as in (4.11), the budget constraints (4.2) take the form

$$
(1-\tau) \cdot c_{1}^{t}=(1-\tau) \cdot E-p_{t} L^{t} \text { and } c_{2}^{t}=\left(a+(1-\pi) p_{t+1}\right) L^{t}+s \cdot\left(E-c_{1}^{t}\right)
$$

A stationary equilibrium is now given by a sequence $\left\{p_{t}\right\}_{t=1}^{\infty}$ of land prices, with a constant price $p_{t}=p$ for all $t$, and an allocation $\left\{c_{2}^{t-1}, c_{1}^{t}, L^{t}\right\}_{t=1}^{\infty}$ such that (i) $c_{2}^{0}=\left(a+p_{1}(1-\pi)\right) L^{0}+S^{0}$, (ii) for $t=1,2, \ldots$, the plan $\left(c_{1}^{t}, c_{2}^{t}, L^{t}\right)$ of generation $t$ maximizes the utility (2.1) under the constraints (4.12), and (iii) the allocation $\left\{c_{2}^{t-1}, c_{1}^{t}, L^{t}\right\}_{t=1}^{\infty}$ satisfies the market-clearing conditions

$$
N\left(c_{2}^{t-1}+c_{1}^{t}\right)=N\left(E+\left(a-\pi p_{t}\right) L^{t}-\tau\left(E-c_{1}^{t}\right)+s\left(E-c_{1}^{t-1}\right)\right)
$$

and

$$
N L^{t}=N L^{t-1}
$$

Proposition 4.3 For any $E, a, \pi, L^{0}$, any $\tau \in[0,1)$ and $s \in[0, \tau)$, there exists a unique stationary equilibrium for $E, a, \pi, L^{0}, \tau, s$, and $S^{0}=s\left(E-c_{1}\right)$. The stationary-equilibrium land price, $p^{* * *}\left(\tau, s, E, a, \pi, L^{0}\right)$, is increasing in E, with

$$
\lim _{E \rightarrow \infty} p^{* * *}\left(\tau, s, E, a, \pi, L^{0}\right)=\infty .
$$

The logic is the same as before. Upon setting $p_{t}=p_{r+1}=p$ and eliminating $p L^{t}$ from the budget constraints in (4.12), one obtains the consolidated constraint

$$
c_{2}^{t}=r(p)(1-\tau)\left(E-c_{1}^{t}\right)+s \cdot\left(E-c_{1}^{t}\right),
$$

which can be rewritten as

$$
c_{1}^{t}+\frac{1}{R(\tau, s, p)} c_{2}^{t}=E
$$

\footnotetext{
${ }^{12}$ If one wants to retain the interpretation of $c_{1}$ as first-period consumption, one can instead endogenize the resources that are available in any given period $t$. For this purpose, replace $E$ by an output variable $y^{t}$ produced by the young generation in period $t$, at a cost equal to $k\left(\frac{y^{t}}{A}\right)$, where $A$ is a productivity parameter, and specify taxes and transfers as $T=\tau \cdot y$ and $S=(1-\sigma) \cdot \tau \cdot y$. If $A$ is very large, with this specification, equilibrium output is very large, and stationary equilibria with $\tau=0$ are dynamically inefficient. Moreover, if the utility functions $u$ and $v$ have elasticities of marginal utility that are less than or equal to one, an increase in $\tau$ induces a Pareto improvement under the same conditions as specified in Proposition 4.4. If $u$ and $v$ have elasticities of marginal utility that are everywhere greater than one, I cannot rule out the possibility that, under the conditions of Proposition 4.4, an increase in $\tau$ induces a large increase in $y$ creating a large additional demand for land, which raises the equilibrium prices of land and lowers the rate of return on land, with an overall negative effect on welfare. The negative welfare fallout is due to the Pareto-relevant pecuniary externality involved in choosing to increase output (partly) in order to raise the demand for land, which translates into higher land prices.
} 
where $r(p)=\frac{a}{p}+1-\pi$, as before, and

$$
R(\tau, s, p):=r(p)(1-\tau)+s .
$$

Equation (3.5) is therefore replaced by the condition

$$
\frac{u^{\prime}\left(E-\frac{1}{R(\tau, s, p)} c_{2}^{t}\right)}{v^{\prime}\left(c_{2}^{t}\right)}=R(\tau, s, p),
$$

which has the same structure as (3.5), except that the rate of return on land $r(p)$ is replaced by $R(\tau, s, p)$, the rate of return on reducing $c_{1}^{t}$ and "investing" a fraction $\tau$ of the reduction in the tax-and-transfer system and a fraction $1-\tau$ of the reduction in land. Given that (4.19) has the same formal structure as (3.5), the arguments used to prove Proposition 3.1 carry over with hardly any change.

Turning to the specification $s=(1-\sigma) \tau$, define

$$
R^{*}(\tau, p):=R(\tau,(1-\sigma) \tau, p)=r(p)+\tau[(1-\sigma)-r(p)]
$$

and notice that $R^{*}(\tau, p)$ is increasing in $\tau$ whenever $r(p)<1-\sigma$. This observation provides the basis for the following result.

Proposition 4.4 Assume that $\sigma<\pi$. If $\frac{a}{p^{*}\left(E, a, \pi, L^{0}\right)}+\sigma<\pi$, then for some $\tau>0$, the allocation $\left\{c_{2}^{t-1}, c_{1}^{t}\right\}_{t=1}^{\infty}$ of consumption levels associated with the stationary equilibrium of Proposition 3.1 is Pareto dominated by the allocation $\left\{\hat{c}_{2}^{t-1}, \hat{c}_{1}^{t}\right\}_{t=1}^{\infty}$ of consumption levels associated with the stationary equilibrium of Proposition $4.3 \tau>0$ and $s=(1-\sigma) \tau$. More generally, for any $\tau$ and $s=(1-\sigma) \cdot \tau$, if the stationary-equilibrium land price $p^{* * *}\left(\tau, s, E, a, \pi, L^{0}\right)$ satisfies

$$
\frac{a}{p^{* * *}\left(\tau, s, E, a, \pi, L^{0}\right)}-\pi+\sigma<0,
$$

then a small increase in $\tau$ and $s=(1-\sigma) \cdot \tau$ induces a Pareto improvement in the stationary-equilibrium allocation of consumption.

The inequality (4.21) implies that

$$
r\left(p^{* * *}\left(\tau, s, E, a, \pi, L^{0}\right)\right)<1-\sigma
$$

so that the implicit rate of return in the tax-and-transfer system is higher than the rate of return on land. In this case, a small increase in $\tau$ and $s=(1-\sigma) \cdot \tau$ raises the overall rate of return on reducing $c_{1}^{t}$ and "investing" a fraction $\tau$ of the reduction in the tax-and-transfer system and a fraction $1-\tau$ of the reduction in land.

As before, the fiscal intervention affects welfare both directly, through the effect of $\tau$ on the consolidated budget constraint, and indirectly, through the induced changes in the land price and the rate of return on land. Given the 
inequality (4.22), the direct effect is always positive. I am unable to show that the indirect effect is always positive, but if it is not, it cannot outweigh the direct effect, i.e., the positive effect of an increase in $\tau$ on $R^{*}(\tau, p)$ is not undone by the associated change in the land price $p$. Thus, I obtain:

Proposition 4.5 If the stationary-equilibrium land price satisfies condition (4.22), a small increase in $\tau$ and $s=(1-\sigma) \cdot \tau$ induces an increase in $R^{*}\left(\tau, p^{* * *}\left(\tau, s, E, a, \pi, L^{0}\right)\right)$ and in second-period consumption $c_{2}$. If the utility function $v(\cdot)$ satisfies the inequality

$$
v^{\prime}(c)+c v^{\prime \prime}(c) \leq 0
$$

for all $c$, the fiscal intervention in Proposition 4.5 also lowers the land price $p^{* * *}\left(\tau, s, E, a, \pi, L^{0}\right)$ and raises the rate of return on land $r\left(p^{* * *}\left(\tau, s, E, a, \pi, L^{0}\right)\right)$.

The curvature condition (4.23) ensures that the income effect of an increase in $R^{*}$ always outweighs the substitution effect on first-period consumption. Thus if (4.22) holds, the increase in $R^{*}$ that is associated with an increase in $\tau$ will necessarily lower the outlay $(1-\tau)\left(E-c_{1}\right)$ for land and therefore reduce the market-clearing land price. If the reverse inequality holds, the substitution effect dominates the income effect, so an increase in $R^{*}$ lowers first-period consumption. I have been unable to rule out the possibility that, if (4.22) holds, the increase in $R^{*}$ that is associated with an increase in $\tau$ can raise the outlay $(1-\tau)\left(E-c_{1}\right)$ for land and therefore the market-clearing land price.

\section{Discussion}

The theoretical model in the preceding analysis is ridiculously simple, even simpler than those of Homburg (1991) and Rhee (1991), let alone Diamond (1965) and Blanchard (2019). In what sense are the results nevertheless relevant for the policy discussion?

I will address this question in several parts. First, I will discuss the generalizability of the analysis. Second, I will discuss the order of magnitude of real-world transaction costs for land. Third, I will discuss the relevance of the dynamicefficiency/inefficiency discussion for the policy debate about public debt.

\subsection{Generalizations}

The simplicity of the model treated in this paper is largely a matter of exposition. Extending the conclusions of the analysis to the settings that have previously been used to discuss dynamic inefficiency and fiscal policy is a routine exercise. Such settings include Homburg's (1991) model in which land and labour jointly serve as inputs into production. They also include models with real capital, i.e. an output of production in periods prior to $t$, serving as an additional input into production in period $t$, as in Diamond (1965), Tirole (1985), Homburg (1991), 
Rhee (1991), and Blanchard (2019). In all these models, the theoretical claim that such inefficiency cannot arise if there is a non-produced durable asset such as land is correct if this asset involves no transaction cost, but incorrect if there is a transaction cost for land that is a small but nonvanishing fraction of the transaction value.

In models with real capital, dynamic inefficiency can also take the form of an overaccumulation of capital, in addition to the excessive consumption of the young studied here. This is obvious if real capital and land are equivalent stores of value so that, in equilibrium, they must bear the same rate of return. In this case, if the real rate of return on land is below the real growth rate of the economy, the real rate of return on capital investments is also below the real growth rate. A Pareto improvement over the laissez-faire allocation can then be achieved reducing young people's capital investments and using the resources that are thereby saved to raise old people's consumption. This intervention makes all generations better off, generation 0 because their consumption is increased, generations $t \geq 1$ because the implicit "return" on providing additional resources for old people's consumption and receiving a similar consumption boost from the next generation is higher than the rate of return on real investments.

The point is less obvious if the return to real capital investments is risky, so capital and land are not equivalent stores of value. In this case, in equilibrium, there must be a risk premium, a wedge between the expected rate of return on real capital and the rate of return on land. With a risk premium causing the expected rate of return on real capital to exceed the rate of return on land, it is quite possible to have laissez-faire equilibria in which the expected rate of return on real capital exceeds the growth rate of the economy but the rate of return on land is smaller than the growth rate, and the laissez-faire equilibrium allocation is dynamically inefficient. An example is given in Appendix B. ${ }^{13}$

In this example, which is basically the model of Propositions $3.1-3.3$ extended to allow for risky real investment, dynamic inefficiency arises because a high value of $E$, the amount of the good in period $t$ that is available to generation $t$, induces a large demand for land as a safe asset. Because the quantity of land is fixed, this large demand translates into a high land price $p$ and a rate of return $r(p)$ on land that is below the growth rate of the economy. Because of risk aversion, however, the expected rate of return on real capital must be higher than $r(p)$ and can exceed the growth rate.

In this specification, there is an overinvestment in real capital because the low rate of return on land induces participants to invest more in real capital. A policy intervention that reduces the need to use land as a safe store of value would raise the equilibrium rate of return on land and thereby cause people to substitute away from real capital, towards land. The reduction in equilibrium

\footnotetext{
${ }^{13}$ Since writing the above, I have shown more generally that conditions for dynamic inefficiency in overlapping-generations models with safe and risky assets depend on comparisons of safe rates of return and growth rates or, if safe assets are not held, comparisons of intertemporal shadow prices for non-contingent changes of consumption levels in subsequent periods and growth rates; see Hellwig (2021).
} 
capital investments is beneficial because people's desires for storing value are satisfied without their having to bear as much risk from their investments in real capital.

Homburg (2014 a) overlooks these considerations. As a "test of overaccumulation", he compares indices of nominal rates of return on risky assets - corporate bond yields for the US and nominal loan rates for the euro area - with nominal growth rates. Finding that most of the time, the rates of return exceeded the growth rates, he concludes that the economies involved followed dynamically efficient growth paths. The preceding considerations show that this conclusion is unwarranted. ${ }^{14}$ It might just be the case that the assets he considered bear returns above growth rates because risk premia are high, whereas the dynamic inefficiency involves an overinvestment in land as a safe asset.

\subsection{Real-World Transaction Costs}

In the real world, the most valuable pieces of land are not traded in isolation but in combination with structures that have been built on them. Unbuilt land, in particular land where zoning prohibits building, is much cheaper than built-up land. If one thinks about the structures as being durable, one can simply reinterpret the asset "land" in the analysis here as a package of "landcum-structure"; the logic of the analysis is unaffected. If one takes account of the endogeneity of the structures, the argument of Diamond (1965) suggests that dynamic inefficiency may involve overinvestment in them. The possibility of decay, or even industrial decline, possibly with toxic leftovers, destroying the usefulness of the structures and possibly even the land puts limits on the assumed durability and therefore on the scope for values to become unbounded as interest rates go to zero. The main point of the analysis may therefore be strengthened when the durable assets in the model are thought of in terms of "land-cum-structure" packages rather than land.

Land-cum-structure packages are heterogeneous, in terms of quality and size of structures and in terms of location. The heterogeneity of the packages goes along with frictions to tradability. Frictions can arise from matching problems, as well as lemons problems. Matching problems arise from the lack of mobility of participants, limits to divisibility, and the inhomogeneity of different units, where differences in location, neighbourhood and makeup can matter greatly.

\footnotetext{
${ }^{14} \mathrm{I}$ am aware that this assessment involves a fundamental criticism of a large literature that began with Abel et al. (1989). In Hellwig (2021), I show why the focus of Abel et al. (1989) on aggregate asset returns is misleading and why, contrary to their claims, the assessment of dynamic inefficiency hinges on comparisons of safe rates of return, or the corresponding intertemporal shadow prices, with growth rates. I also show that, in a stationary environment, the condition for dynamic efficiency in Abel et al. (1989), which rests on a comparison of capital investments and payouts, is in fact a special case of my condition comparing safe rates of return and growth rates. Whereas Abel et al. (1989) based their empirical analysis on the comparison of capital investments and payouts, much of the subsequent literature, including Homburg (2014 a) returned to comparing (risky) rates of return and growth rates, identifying dynamic inefficiency with a situation where aggregate (mean) rates of return are below growth rates. This procedure has no proper welfare foundation.
} 
Lemons problems arise from asymmetries of information about the soundness of structures, or about toxic residues from past activities.

Such frictions contribute substantially to transaction costs for land-cumstructure packages in the real world. In the United States, transaction costs for real-estate are on the order of ten percent of the value of the transaction. More than half of this cost, six percent of the value of the transaction, goes to the real-estate brokers for matching up buyers and sellers. The remainder is spent on legal fees, recording fees, title search and insurance (together 1.5 - 3.5\%) and taxes (up to $1.5 \%$ ). In Germany, transaction costs range from nine to sixteen percent of the value of the transaction, with brokerage fees, including valueadded tax, ranging from $3.57 \%$ to $7.14 \%$, depending on bargaining powers, notarization and registration costs ranging from $2 \%$ to $3 \%$, and taxes ranging from $3.5 \%$ to $6.5 \%$, depending on regional legislation. ${ }^{15}$ The transaction cost $\pi p L$ in the analysis of this paper can be seen as a way of taking account of such frictions without actually modelling them. ${ }^{16}$

Is it legitimate to link the numbers for real-world transaction costs to the transaction cost term $\pi p$ in the model? After all, the model has no financial sector that would allow for a separation between the need for a store of value, the ownership of the real assets and the use of the assets. Some of the impediments to tradability in real-estate markets, in particular, the matching frictions and the need for costly real-estate agents, involve the specifics of the use of the assets while holding them, rather than their ability to store value and make value available through resale at a later time. Financial institutions such as real-estate investment trusts or pension funds provide for a separation of the store-of-value function to investors from the provision of services to users. However, such institutions are not able to avoid the costs of real-estate transactions altogether; moreover, they have their own costs, including the agency costs associated with the management of real-estate portfolios. In some cases, for example with nontraded public real-estate investment trusts, these costs are on the same order of magnitude as the above numbers for real-estate transactions.

The assumption that the transaction cost is linear in $p L$ is counterfactual. For real-world transaction costs, some of the ranges indicated reflect nonlinearities in transaction cost schedules. Such nonlinearities may be due to statutes,

\footnotetext{
${ }^{15}$ Data from Global Property Guide 2020, https://www.globalpropertyguide.com/faq/guidetransaction-costs, accessed March 9, 2020. In France, total transaction costs can be much higher yet, ranging from $8 \%$ to $29 \%$, with a $3 \%-10 \%$ range for real estate agents and a 3 $\%$ to $10 \%$ range for notarization fees.

${ }^{16}$ In the German debate about the potential role of government debt as an antidote to dynamic inefficiency, von Weizsäcker (2014) and von Weizsäcker and Krämer (2019) have also argued that land is not well suited for serving as a store of value whose availability can prevent interest rates from dropping below growth rates. In addition to the issue of inhomogeneity and potential information asymmetry, they point to the risks attached to returns and to political risks, including risks of total or partial expropriation, which are the larger, the higher the value of land is. They suggest that these risks call for premia on the order of 7 percent p.a., so that observed rates of return on real estate would imply negative interest rates for safe investments. They also suggest that the political risks put bounds on the extent to which price appreciation for land may be sufficient to deal with the entire demand for a store of value. On the latter point, see also the discussion at the end of Section 2 above.
} 
scale economies or greater bargaining powers of parties with large-value transactions. However, for some components of transaction costs, e.g., components reflecting liability risks of notaries and real-estate agents in situations of asymmetric information, the scope for cost degressions is likely to be limited.

Even with nonlinear transaction costs, the conclusions of this paper remain as long as transaction costs per unit of land exceed the one-period per-unit real return $a$ when $p$ is sufficiently large. Given the element of intermediaries' liability risks in transaction costs, I do not consider this condition to be outlandish. However, because observed transactions involve finite values, we do not have any empirical evidence on what transaction costs would be at very high transaction values. Any statement about the behaviour of transaction costs at arbitrarily large transaction values would have to be based on speculation, rather than observation. This qualification applies to both sides of the debate.

In the overlapping-generations model, the need for a store of value arises solely from the desire to provide for retirement. In the real world, there are multiple reasons for why one might need a store of value, for example uncertainty and precautionary saving, or lumpy transactions that are spaced apart in time. Also real-world holding periods are endogenous and differ depending on why value is stored and what assets are held. ${ }^{17}$

The multiplicity of needs for storing value and the development of strategies and institutions for adapting different kinds of assets to these needs may however be more important for our understanding of the financial system than for the policy debate to which this paper is attached. The numbers presented by von Weizsäcker (2014) as well as von Weizsäcker and Krämer (2019) indicate that saving for retirement has contributed a substantial part of the strong worldwide growth of private savings over the past few decades, driven by demographic change as well as increasing incomes, in emerging economies as well as OECD countries. Given these findings, reliance on a model that focuses on retirement provision as the cause of a need for storing value seems quite appropriate.

With a focus on retirement provision, and the costs of alternative arrangements, it is of interest to note that, in relative terms, administrative costs of pay-as-you-go systems tend to be fairly low. In the United States, the share of total administrative costs of old-age and disability insurance in expenditures has declined from some slightly more than $2 \%$ in the $1950 \mathrm{~s}$ and $1960 \mathrm{~s}$ to $0.7 \%$ in recent years, $0.4 \%$ for old-age insurance and $1.9 \%$ for disability insurance. ${ }^{18}$ In Germany, the share of total administrative costs in expenditures is on the order of two percent. Even without taking account of the taxes involved, these numbers are significantly lower than the per-unit-of-value transaction costs for real estate. Thus the condition in Propositions 4.2 and 4.4 that the dissipation coefficient $\sigma$ in a fiscal intervention be less than the transaction cost parameter $\pi$ for land is not outlandish. The reason is not that the government is so

\footnotetext{
${ }^{17}$ For example, assets with high transaction costs are relatively unattractive if holding periods are expected to be short and relatively attractive if holding periods are expected to be long.

${ }^{18}$ See https://www.ssa.gov/oact/STATS/admin.html. I am grateful to Peter Diamond for this reference.
} 
much more efficient but that the pay-as-you-go system, despite the flaws it may otherwise have, does not have to deal with asset quality and asset management.

None of this is to be interpreted as taking a position on the Blanchard-von Weizsäcker proposition that the current macroeconomic environment calls for an expansion of public debt. An assessment of that proposition would have to encompass other forms of fiscal intervention in the provision of stores of value, from tradable debt securities to fiat money. Such an assessment would also have to take into account that, in Proposition 4.2, the inequality $\sigma<\pi$ is necessary, but not sufficient for fiscal intervention to make for a Pareto improvement.

However, the preceding analysis forestalls the killer argument that, because dynamic inefficiency cannot arise in an economy with land, we know for sure that a state of affairs with interest rates below growth rates cannot last and therefore should not be made a basis for public policy. The killer argument is correct when there are no transaction costs for land, but is incorrect if there is even a small per-unit-of-value transaction cost.

\subsection{Paper Assets and the Empirics of Dynamic Inefficiency}

Despite the preceding disclaimer (which was already in the previous version of this paper), an anonymous referee has requested that I provide empirical evidence to the effect that, after taking account of transaction costs, the real rate of return on land is actually negative. The referee confuses the question whether, in an economy with land, dynamic inefficiency can be ruled out on $a$ priori grounds with the question whether we actually are in a situation involving dynamic inefficiency of observed outcomes.

The preceding analysis, like Homburg (1991) and the theoretical part of Homburg (2014 a), involves the first question. Both are concerned with the properties of equilibrium allocations in a fictitious world in which the fundamentals of the economy cause the demand for a store of value to be very large. By their very nature, such claims about fictitious worlds do not lend themselves to empirical investigation. Nevertheless, they can be important in policy discussions; see, e.g., Sinn's (2020) invocation of Homburg's theoretical arguments in his critique of von Weizsäcker and Krämer (2019). Therefore, it is important to evaluate the scope of such claims, which is the point of this paper.

The referee's request is also problematic when taken on its own terms. Suppose that an empirical analysis were to show that actual outcomes are dynamically efficient. Would that prove that dynamic inefficiency plays no role in the real world?

As an example, consider Homburg's (2014 a) claim that his comparison of rates of return and rates of growth warrants the conclusion that actual outcomes are dynamically efficent. Above, I have argued that, because of asset heterogeneity, his empirical analysis is not actually sufficient to establish this claim. ${ }^{9}$ But suppose nevertheless, for the sake of the argument, that his analysis was sufficient to establish that observed allocations are dynamically efficient.

${ }^{19}$ Homburg (2014 a) also points to the importance of real estate as an asset class in advanced 
What exactly would that prove? Would it prove that theoretical concerns about dynamic inefficiency are irrelevant? Or could it be the case that real-world outcomes are dynamically efficient because real-world economies exhibit features that are not in the theoretical models and that matter because, without them, laissez-faire allocations would be dynamically inefficient?

In the real world, in contrast to the theoretical models in this paper and in Homburg (1991, 2014 a), we have paper assets such as fiat money and debt denominated in units of fiat money. What happens in the theoretical models if we allow for such assets? Typical results show that equilibrium values of such assets are positive if and only if, in their absence, laissez-faire allocations would be dynamically inefficient. ${ }^{20}$

For the model of this paper, the following result with fiat money makes this point formally. Suppose that each member of the old generation at $t=1$ has an endowment of $M^{0}>0$ units of fiat money, in addition to $L^{0}$ units of land. Suppose also that people born in periods $t=1,2, \ldots$ have no initial endowment of money, but can acquire money at a per-unit price equal to $q_{t}$ units of the current consumption good in period $t$, and can sell it at a per-unit price equal to $q_{t+1}$ units of the current consumption good in period $t+1$. With this modification of the original model, the constraints (2.2) take the form

$$
c_{1}^{t}=E-p_{t} L^{t}-q_{t} M^{t} \text { and } c_{2}^{t}=\left(a+p_{t+1}(1-\pi)\right) L^{t}+q_{t+1} M^{t},
$$

where $M^{t}$ is the amount of fiat money that a member of generation $t$ holds at the end of period $t$.

A stationary equilibrium is now given by a sequence $\left\{p_{t}, q_{t}\right\}_{t=1}^{\infty}$ of price pairs satisfying $\left(p_{t}, q_{t}\right)=(p, q)$ for all $t$, for some $p, q$, and an allocation $\left\{c_{2}^{t-1,} c_{1}^{t}, L^{t}, M^{t}\right\}_{t=1}^{\infty}$ such that (i) $c_{2}^{0}=\left(a+p_{1}(1-\pi)\right) L^{0}+q_{1} M^{0}$ and, for $t=1,2, \ldots$, the vector $\left(c_{1}^{t}, c_{2}^{t}, L^{t}, M^{t}\right)$ maximizes the utility (2.1) under the constraints (5.1), and, moreover, (ii) for $t=1,2, \ldots$, the allocation $\left\{c_{2}^{t-1,} c_{1}^{t}, L^{t}, M^{t}\right\}_{t=1}^{\infty}$ satisfies (2.3) and (2.4) as well as

$$
N M^{t}=N M^{t-1} .
$$

Trivially, this model always has a stationary equilibrium with $q_{t}=0$ and $M^{t}=M^{0}$ for all $t .^{21}$ The question is under what circumstances there also exist monetary equilibria, i.e. equilibria in which the prices $q_{t}$ are bounded away from zero or, with stationarity, the common value $q$ of the prices $q_{1}, q_{2}, \ldots$ is strictly positive.

Proposition 5.1 For any $E, a, \pi, L^{0}, M^{0}$, a stationary monetary equilibrium exists if and only if, in the stationary equilibrium of Proposition 3.1, the interest rate, $\frac{a}{p^{*}\left(E, a, \pi, L^{0}\right)}-\pi$, is strictly negative. The stationary monetary equilibrium

economies. This observation in itself says nothing about the scope for land and land prices to accommodate dramatic increases in the demand for a store of value so that equilibrium allocations remain dynamically efficient.

${ }^{20}$ See, for example, Allais (1947), Samuelson (1958), Grandmont and Laroque (1973), Tirole (1985), Santos and Woodford (1997).

${ }^{21}$ With $q_{t}=0$ for all $\mathrm{t}$, the stationary equilibrium of Proposition 3.1 is also a stationary equilibrium of the expanded model. 
is unique; it involves the constant land price $p=\frac{a}{\pi}$, a consumption allocation with $\left(c_{1}^{t}, c_{2}^{t}\right)=\left(c_{1}, c_{2}\right)$ for all $t$, where $\left(c_{1}, c_{2}\right)$ maximizes $u\left(c_{1}\right)+v\left(c_{2}\right)$ under the constraint $c_{1}+c_{2}=E$, and a constant real value of money $q_{1}=\left[E-c_{1}-\right.$ $\left.\frac{a}{\pi} L^{0}\right] / M^{0}$ for all $t$. The equilibrium allocation Pareto-dominates the stationaryequilibrium allocation in Proposition 3.1 and is itself Pareto efficient.

Given this result, the very presence of fiat money in the real world provides prima facie evidence that dynamic inefficiency is a real-world problem. Empirical findings to the effect that real-world outcomes are dynamically efficient beg the question whether the efficiency is due to the effectiveness of fiat money and assets denominated in fiat money in eliminating the problem of dynamic inefficiency or whether they are due to dynamic inefficiency being a priori impossible. Arguments in support of the second alternative would have to provide an alternative explanation of the role of paper assets in the economy.

\subsection{The Land Argument - a Red Herring in the Policy Debate?}

For the policy debate, results like Proposition 5.1 raise the question why changes in the demand for a store of value would call for policy interventions with active management of the supplies of paper assets. If equilibrium allocations in economies with paper assets are dynamically efficient, isn't it enough to have prices adjust so that the "real" quantities of paper assets adjust automatically when demands change?

In a sense, this is a version of the land argument, except that it is now applied to paper assets. The call for active policy intervention, such as an expansion of government debt in response to increased needs for stores of value, presumes that the problem cannot be solved by adjustments in market prices. In Proposition 5.1, however, the real value $q$ of the available stock of fiat money can be arbitrarily large so, no matter what $M^{0}$ may be, a suitably high value of $q$ will ensure that an efficient outcome is implemented. ${ }^{22}$

At this point, the question arises whether we should think about the policy proposals of Blanchard (2019) or von Weizsäcker and Krämer (2019) in terms of market equilibrium or in terms of market disequilibrium. If one thinks about them in terms of market equilibrium, it seems appropriate to start from the fact that, with market systems that are incomplete even with sequential trading, equilibrium outcomes may not be fully efficient, but only constrained efficient so pecuniary externalities may be relevant and may provide a basis for active policy interventions that yield improvements over laissez-faire outcomes. However, there is a difficulty with this argument because inefficiencies in incomplete market systems are usually derived from idiosyncratic, agent-specific problems

\footnotetext{
${ }^{22} \mathrm{~A}$ second referee has suggested that the arguments concerning land are also applicable to gold. In fact they are applicable to all assets in positive net supply, a property that fiat money and gold share with land.
} 
of adverse selection or moral hazard, but policy interventions concern aggregates.

An alternative approach might consider the costs that are associated with price adjustments, allowing for the possibility that avoidance of such costs may induce market disequilibria. The argument would be akin to Keynes's discussion of changes in money wages in Chapter 19 of the General Theory. Without denying that reductions in money wages might eventually reduce unemployment, Keynes explains that such an effect would not be due to the standard partialequilibrium demand-supply mechanism, but to general-equilibrium effects that can just as well be obtained by increases in the quantity of central-bank money. After elaborating on the frictions attached to reductions in money wages, he argues that it would be much easier to achieve the desired effects by increases in the money supply.

The proposition that increases in the demand for a store of value are appropriately taken care of by the price system presumes that, if such increases occur, prices adjust quickly so that the real value of paper assets goes up to accommodate the additional demand. In the theoretical model, there would be a one-shot dramatic decrease in the money prices of real goods and services (an increass in $q$ ), and after that, the system would proceed on a new equilibrium path. In practice, we do not see such dramatic deflationary shocks; in fact, market participants as well as outside observers are often unable to distinguish between price responses to exogenous developments and endogenous, disequilibrium price dynamics. Keynes's concerns about frictions are also relevant here.

One point that Keynes did not discuss concerns the impact of changes in the real value of fiat money on outcomes under nominal contracts, in particular debt contracts. In the theoretical part of his book, Mises (1924/1953) suggested that it is desirable to keep the value of money stable in order to immunize debtors as well as creditors in debt contracts from shocks to the purchasing power of money. ${ }^{23}$ This is not just an issue of risk allocation ex ante, but also an issue of risk incidence ex post as deflation can endanger borrower solvency, with ensuing damage for asset markets and the overall economy, as in Irving Fisher's account of debt deflation. Here again, a question would be why debt contracts (as well as other nominal contracts) are not adjusted to take care of this kind of risk, e.g. through indexing.

As far as I can tell, we do not have convincing answers to these questions one way or the other. However, it seems to me that these are the questions that need to be answered if we are to make progress in the policy debate. From this perspective, the focus on the role of land in considerations of dynamic inefficiency seems like a red herring. However, the role that it plays in the policy debate is important enough to warrant showing that the "refutation" of Blanchard or von Weizsäcker and Krämer by a simple reference to land is not robust to the introduction of transaction costs.

The preceding discussion refers to fiat money rather than public debt. A

\footnotetext{
${ }^{23}$ In contrast, the policy part of the book advocates a gold standard regime even though the theoretical analysis had deplored the instability associated with a dependence on gold. The aim of keeping politics out of monetary policy superseded the theoretical findings.
} 
policy discussion about paper assets as a means to provide stores of value must actually refer to both. This is not just a question of generality. The two policy areas are intimately linked: First, in the absence of "helicopter money", i.e., a central-bank competence to increase central-bank money by transfer payments, the amount of public debt that is outstanding affects the scope for increasing the amount of money in the economy through open market operations. Second, the zero lower bound for the interest rate on public debt is a consequence of people's ability to substitute fiat money for debt securities; at this bound, investors treat debt securities and fiat money as close substitutes so that, for policy analysis, the aggregate of the two may be the relevant variable to look at. Both considerations suggest that discussions about activism in monetary policy and activism in public debt policy should be treated as one integrated whole. 


\section{A Proofs}

Proof of Propositions 3.1. I first show that, under the specified assumptions, for any $E, a, \pi, L^{0}$, the equation

$$
u^{\prime}\left(E-p L^{0}\right) \cdot p=v^{\prime}\left((a+p(1-\pi)) L^{0}\right) \cdot(a+p(1-\pi))
$$

has a unique solution $p^{*}\left(E, a, \pi, L^{0}\right)$. This equation is equivalent to the equation

$$
u^{\prime}\left(E-p L^{0}\right)=v^{\prime}\left((a+p(1-\pi)) L^{0}\right) \cdot \frac{a+p(1-\pi)}{p} .
$$

If $p$ is close to zero, the left-hand side of (A.2) is close to $u^{\prime}(E)$, and the right-hand side of (A.2) is very large. If $p$ is close to (but less than) $E / L^{0}$, the left-hand side of (A.2) is very large, and the right-hand side of (A.2) is close to $v^{\prime}\left(a L^{0}+(1-\pi) E\right) \cdot\left(a+(1-\pi) E / L^{0}\right)$. Because both sides of (A.1) are continuous in $p$, the intermediate-value theorem implies that (A.2) has a solution. Under the given assumptions, the left-hand side of (A.2) is increasing in $p$, and the right-hand side is decreasing in $p$. Therefore the solution to (A.2) is unique.

Next I note that, if $p_{t+1}=p_{t}=p$, then a necessary and sufficient condition for a solution to the maximization problem of generation $t$ is given by the equation

$$
u^{\prime}\left(E-p L^{t}\right) \cdot p=v^{\prime}\left((a+p(1-\pi)) L^{t}\right) \cdot(a+p(1-\pi)),
$$

in combination with the constraints in (2.2). Hence if $p$ is equal to the solution $p^{*}\left(E, a, \pi, L^{0}\right)$ to equation (A.1), a necessary and sufficient condition for a solution to the maximization problem of generation $t$ is to have

$$
L^{t}=L^{0},
$$

as well as

$$
c_{1}^{t}=E-p^{*}\left(E, a, \pi, L^{0}\right) L^{0}
$$

and

$$
c_{2}^{t}=\left(a+p^{*}\left(E, a, \pi, L^{0}\right)(1-\pi)\right) L^{0} .
$$

At this point, it is easy to see that the triples $\left(c_{2}^{t-1}, c_{1}^{t}, L^{t}\right)$ that are given by (A.4) - (A.6) satisfy conditions (2.3) and (2.4) for all $t$. Hence, by setting $p_{t}=$ $p^{*}\left(E, a, \pi, L^{0}\right)$ for all $t$ and using (A.4) - (A.6) to specify an allocation, one obtains a stationary equilibrium. Uniqueness follows upon observing that the equilibrium condition (2.4) implies (A.4) for all $t$, so (A.3) is equivalent to (A.1), which has $p^{*}\left(E, a, \pi, L^{0}\right)$ as its only solution.

To prove the claimed comparative-statics properties, I note that under the stated assumptions, an increase in $E$ makes the left-hand side of (A.2) go down without affecting the right-hand side. Since, by the above argument, the difference between the left-hand side and the right-hand side is increasing in $p$. Following an increase in $E$, therefore, an increase in $p$ is required to restore 
equality. An increase in $L^{0}$ makes the left-hand side of (A.2) go up and the right-hand side go down, so a decrease in $p$ is needed to restore equality.

To see that $\lim _{E \rightarrow \infty} p^{*}\left(E, a, \pi, L^{0}\right)=\infty$, it suffices to observe that, if $p^{*}\left(E, a, \pi, L^{0}\right)$ were bounded as $E$ goes out of bounds, then, for $p=p^{*}\left(E, a, \pi, L^{0}\right)$, the left-hand side of (A.1) would converge to zero and the right-hande side would converge to a positive limit. Similarly, if $p^{*}\left(E, a, \pi, L^{0}\right)$ were bounded as $L^{0}$ becomes small, the left-hand side of (A.1) would converge to $u^{\prime}(E)$ and the right-hand side of (A.1) would go out of bounds. In either case, the validity of (A.1) at $p=p^{*}\left(E, a, \pi, L^{0}\right)$ would be violated. Hence $p^{*}\left(E, a, \pi, L^{0}\right)$ must satisfy $(3.1)$.

Proposition 3.2 follows immediately from Proposition 3.1.

Proof of Proposition 3.3 (a). The line of argument is the same as in the proof of the First Welfare Theorem for competitive equilibria in a complete market system. Given that, for any $t \geq 1$, the triple $\left(c_{1}^{t}, c_{2}^{t}, L^{t}\right)$ maximizes (2.1) subject to (2.2), it must also be the case that, for any $t \geq 1$, the pair $\left(c_{1}^{t}, c_{2}^{t}\right)$ maximizes (2.1) subject to

$$
c_{1}^{t}+\frac{p_{t}}{a+p_{t+1}(1-\pi)} c_{2}^{t} \leq E .
$$

Given the stationarity of the equilibrium, with $p_{t}=p^{*}\left(E, a, \pi, L^{0}\right)$ for all $t$, and given the strict monotonicity of (2.1), this constraint may be rewritten as

$$
c_{1}^{t}+(1+r)^{-1} c_{2}^{t}=E,
$$

where

$$
r:=\frac{a}{p^{*}\left(E, a, \pi, L^{0}\right)}-\pi .
$$

If statement (a) of the proposition is false, there exists an alternative allocation $\left\{\hat{c}_{2}^{t-1}, \hat{c}_{1}^{t}\right\}_{t=1}^{\infty}$ of nonnegative consumption levels satisfying (3.8) for all $t$ such that

$$
\hat{c}_{2}^{0} \geq c_{2}^{0}
$$

and, for $t=1,2, \ldots$,

$$
u\left(\hat{c}_{1}^{t}\right)+v\left(\hat{c}_{2}^{t}\right) \geq u\left(c_{1}^{t}\right)+v\left(c_{2}^{t}\right),
$$

and at least one of the inequalities in (A.10) and (A.11) is strict. Because, for $t \geq 1$, the pair $\left(c_{1}^{t}, c_{2}^{t}\right)$ maximizes (2.1) subject to (A.8), it follows that, for $t \geq 1$

$$
\hat{c}_{1}^{t}+(1+r)^{-1} \hat{c}_{2}^{t} \geq c_{1}^{t}+(1+r)^{-1} c_{2}^{t}
$$

and at least one of the inequalities in (A.10) and (A.12) is strict. The inequalities in (A.12) are equivalent to the inequalities

$$
\frac{1}{(1+r)^{t-1}} \hat{c}_{1}^{t}+\frac{1}{(1+r)^{t}} \cdot \hat{c}_{2}^{t} \geq \frac{1}{(1+r)^{t-1}} c_{1}^{t}+\frac{1}{(1+r)^{t}} \cdot c_{2}^{t} .
$$


Upon adding these inequalities over $t=1,2, \ldots$ and adding (A.10), using the fact that at least one of the inequalities is strict, one obtains

$\hat{c}_{2}^{0}+\sum_{t=1}^{\infty}\left[\frac{1}{(1+r)^{t-1}} \hat{c}_{1}^{t}+\frac{1}{(1+r)^{t}} \cdot \hat{c}_{2}^{t}\right]>c_{2}^{0}+\sum_{t=1}^{\infty}\left[\frac{1}{(1+r)^{t-1}} c_{1}^{t}+\frac{1}{(1+r)^{t}} \cdot c_{2}^{t}\right]$,

where the infinite sums are well defined because $r>0$ and the consumption variables are uniformly bounded by $E+a L^{0}$. Upon reordering sums, one finds that (A.14) is equivalent to the inequality

$\sum_{t=1}^{\infty}\left[\frac{1}{(1+r)^{t-1}} \hat{c}_{1}^{t}+\frac{1}{(1+r)^{t-1}} \cdot \hat{c}_{2}^{t-1}\right]>\sum_{t=1}^{\infty}\left[\frac{1}{(1+r)^{t-1}} c_{1}^{t}+\frac{1}{(1+r)^{t-1}} \cdot c_{2}^{t-1}\right]$,

which is incompatible with (3.8) holding for all $t \geq 1$. The assumption that statement (a) of the proposition is false has thus led to a contradiction.

Proof of Proposition 3.3 (b). Given the stationarity of the equilibrium, let $c_{1}^{*}, c_{2}^{*}$ be the common values of $c_{1}^{t}, c_{2}^{t-1}, t=1,2, \ldots$ By the first-order condition (3.5) and the assumption that $\frac{a}{p^{*}\left(E, a, \pi, L^{0}\right)}-\pi<0$, there exists a pair $\left(\hat{c}_{1}^{*}, \hat{c}_{2}^{*}\right)$ such that

$$
\begin{gathered}
\hat{c}_{1}^{*}+\hat{c}_{2}^{*}=c_{1}^{*}+c_{2}^{*}, \\
\hat{c}_{1}^{*}<c_{1}^{*}, \hat{c}_{2}^{*}>c_{2}^{*},
\end{gathered}
$$

and

$$
u\left(\hat{c}_{1}^{*}\right)+v\left(\hat{c}_{2}^{*}\right)>u\left(c_{1}^{*}\right)+v\left(c_{2}^{*}\right) .
$$

Upon setting $\left(\hat{c}_{2}^{t-1}, \hat{c}_{1}^{t}\right)=\left(\hat{c}_{2}^{*}, \hat{c}_{1}^{*}\right)$ for all $t$, one obtains an allocation $\left\{\hat{c}_{2}^{t-1}, \hat{c}_{1}^{t}\right\}_{t=1}^{\infty}$ of consumption levels that satisfies (3.8) for all $t$ and that Pareto dominates the equilibrium allocation $\left\{c_{2}^{t-1}, c_{1}^{t}\right\}_{t=1}^{\infty}$. Therefore the equilibrium allocation $\left\{c_{2}^{t-1}, c_{1}^{t}\right\}_{t=1}^{\infty}$ is not weakly efficient.

Proof of Proposition 4.1. For uniqueness and for the comparative statics with respect to $E$, as well as the limit (4.8), the argument is the same as in the proof of Proposition 3.1, with equation (A.2) replaced by the equation

$$
u^{\prime}\left(E-p L^{0}-T\right)=v^{\prime}\left((a+p(1-\pi)) L^{0}+S\right) \cdot \frac{a+p(1-\pi)}{p} .
$$

The details are left to the reader. For the comparative statics with respect to $T$ and $S$, it suffices to observe that increases in $T$ and $S$ make the difference between the left-hand side and the right-hand side of (A.19) go up, so a decrease in $p$ is needed to restore equality in (A.19).

Proof of Proposition 4.2. Dropping the dependence on other parameters, for any $T$, let $p(T), \hat{c}_{1}(T)$ and $\hat{c}_{2}(T)$ be the common values of $p_{t}, \hat{c}_{1}^{t}$ and $\hat{c}_{2}^{t-1}, t=$ $1,2, \ldots$, in the stationary equilibria with parameters $T, S=(1-\sigma) T, E, a, \pi, L^{0}$. 
By the implicit function theorem to (A.19), $p(T)$ is continuously differentiable; its derivative is:

$$
p^{\prime}(T)=-\frac{1}{L^{0}} \frac{u^{\prime \prime}\left(\hat{c}_{1}(T)\right)+v^{\prime \prime}\left(\hat{c}_{2}(T)\right)(1-\sigma) \frac{a+p(1-\pi)}{p}}{u^{\prime \prime}\left(\hat{c}_{1}(T)\right)+v^{\prime \prime}\left(\hat{c}_{2}(T)\right) \frac{a+p(1-\pi)}{p}-v^{\prime}\left(\hat{c}_{2}(T)\right) \frac{a}{p^{2}}} .
$$

Thus, under the given assumptions on $u$ and $v$,

$$
-1<p^{\prime}(T) L^{0}<0
$$

for all $T$.

Since

$$
\hat{c}_{1}(T)=E-p(T) L^{0}-T
$$

and

$$
\begin{aligned}
\hat{c}_{2}(T) & =(a+p(T)(1-\pi)) L^{0}+(1-\sigma) T \\
& =a L^{0}+(1-\pi)\left(p(T) L^{0}+T\right)+(\pi-\sigma) T,
\end{aligned}
$$

it follows that $\hat{c}_{1}(T)$ is decreasing and $\hat{c}_{2}(T)$ is increasing in $T$.

To assess the welfare implications of the fiscal intervention, I note that people born in date 0 , i.e., the old generation at date 1 , benefit from the change because their consumption is equal to $\hat{c}_{2}(T)$, which goes up with $T$. For people born in $t \geq 1$, the effects of $T$ on the lifetime

$$
V(T)=u\left(E-p(T) L^{0}-T\right)+v\left((a+p(T)(1-\pi)) L^{0}+(1-\sigma) T\right)
$$

are computed as

$$
\begin{aligned}
V^{\prime}(T)= & -u^{\prime}\left(\hat{c}_{1}(T)\right)+v^{\prime}\left(\hat{c}_{2}(T)\right) \cdot(1-\sigma) \\
& -u^{\prime}\left(\hat{c}_{1}(T)\right) \cdot p^{\prime}(T) L^{0}+v^{\prime}\left(\hat{c}_{2}(T)\right) \cdot(1-\pi) \cdot p^{\prime}(T) L^{0} .
\end{aligned}
$$

Upon using (A.19) to substitute for $u^{\prime}\left(\hat{c}_{1}(T)\right)$, one further obtains

$$
\begin{aligned}
V^{\prime}(T)= & v^{\prime}\left(\hat{c}_{2}(T)\right) \cdot\left[(1-\sigma)-\frac{a}{p(T)}-1+\pi\right] \\
& -v^{\prime}\left(\hat{c}_{2}(T)\right) \frac{a}{p(T)} \cdot p^{\prime}(T) L^{0} .
\end{aligned}
$$

The second term on the right-hand side is positive because $p^{\prime}(T)<0$. The first term on the right-hand side is also positive if

$$
1-\sigma>\frac{a}{p(T)}+1-\pi
$$

or, equivalently,

$$
\frac{a}{p^{* *}\left(T, S, E, a, \pi, L^{0}\right)}+\sigma<\pi .
$$

The proposition follows immediately. 
From (A.20), one also finds that $p^{\prime}(T) L^{0}>-1$. Thus (A.26) implies $V^{\prime}(T)<$ $v^{\prime}\left(\hat{c}_{2}(T)\right)[\pi-\sigma]$. If $\pi \leq \sigma$, it follows that $V^{\prime}(T)<0$, as claimed in the text.

Proof of Proposition 4.3. The argument is the same as in the proof of Proposition 3.1, with equation (A.2) replaced by the equation

$$
u^{\prime}\left(E-\frac{p L^{0}}{1-\tau}\right)=v^{\prime}\left(R(\tau, s, p) p L^{0}\right) \cdot R(\tau, s, p),
$$

where $R(\tau, s, p)=(1-\tau) r(p)+s$. The left-hand side of (A.27) is increasing in $p$. The term $R(\tau, s, p)$ on the right-hand side is decreasing in $p$; the term $R(\tau, s, p) p L^{0}$ inside the marginal utility on the right-hand side is increasing in $p$, so the right-hand side altogether is decreasing in $p$. Therefore equation (A.27) has at most one solution. Existence of a solution follows from boundary behaviour and the intermediate-value theorem, as in the proof of Proposition 3.1. For monotonicity with respect to $E$ and the limit in (4.15), the argument is also the same as in the proof of Proposition 3.1. The details are left to the reader.

The proof of Propositions 4.4 and 4.5 will make use of the following lemma.

Lemma A.1 Let $\left(c_{1}(R), c_{2}(R)\right)$ maximize $u\left(c_{1}\right)+v\left(c_{2}\right)$ under the constraint $c_{1}+\frac{1}{R} c_{2}=E$. Then $c_{2}(R)$ is increasing in $R ; c_{1}(R)$ is increasing in $R$ if $v^{\prime}(c)+c v^{\prime \prime}(c) \leq 0$ for all $c$ and decreasing in $R$ if $v^{\prime}(c)+c v^{\prime \prime}(c)>0$ for all $c$.

Proof. The first-order condition for $\left(c_{1}(R), c_{2}(R)\right)$ is

$$
u^{\prime}\left(c_{1}(R)\right)=R v^{\prime}\left(c_{2}(R)\right) .
$$

Total differentiation yields

$$
u^{\prime \prime}\left(c_{1}(R)\right) d c_{1}=R v^{\prime \prime}\left(c_{2}(R)\right) d c_{2}+v^{\prime}\left(c_{2}(R)\right) d R .
$$

From the constraint, we also have

$$
d c_{2}=-R d c_{1}+\left(E-c_{1}(R)\right) d R .
$$

Upon combining (A.29) and (A.30), one obtains

$$
\frac{d c_{1}}{d R}=\frac{v^{\prime}\left(c_{2}(R)\right)+c_{2}(R) v^{\prime \prime}\left(c_{2}(R)\right)}{u^{\prime \prime}\left(c_{1}(R)\right)+R^{2} v^{\prime \prime}\left(c_{2}(R)\right)}
$$

and

$$
\frac{d c_{2}}{d R}=-\frac{v^{\prime}\left(c_{2}(R)\right)}{u^{\prime \prime}\left(c_{1}(R)\right)+R^{2} v^{\prime \prime}\left(c_{2}(R)\right)}+\frac{c_{2}(R)}{R} \cdot \frac{u^{\prime \prime}\left(c_{1}(R)\right)}{u^{\prime \prime}\left(c_{1}(R)\right)+R^{2} v^{\prime \prime}\left(c_{2}(R)\right)} .
$$

The lemma follows immediately. 
Proof of Propositions 4.4 and 4.5. Dropping the dependence on other parameters, for any $\tau$, let $p(\tau), \hat{c}_{1}(\tau)$ and $\hat{c}_{2}(\tau)$ be the common values of $p$, $\hat{c}_{1}^{t}, \hat{c}_{2}^{t-1}, t=1,2, \ldots$, in the stationary equilibria with parameters $\tau, s=(1-$ $\sigma) \tau, E, a, \pi, L^{0}$. I first show that, if $r(p(\tau))<1-\sigma$, then $R^{*}(\tau, p(\tau))$ is increasing in $\tau$. For suppose that, for some $\tau$ and $\Delta>0$, we have

$$
R^{*}(\tau, p(\tau)) \geq R^{*}(\tau+\Delta, p(\tau+\Delta)) .
$$

Because, with $r(p(\tau))<1-\sigma, R^{*}(\tau, p)$ is increasing in $\tau$ and decreasing in $p$, it follows that $p(\tau+\Delta)>p(\tau)$. Then also $R^{*}(\tau+\Delta, p(\tau+\Delta)) \cdot p(\tau+\Delta)$, and therefore

$$
\begin{aligned}
\hat{c}_{2}(\tau+\Delta) & =R^{*}(\tau+\Delta, p(\tau+\Delta)) \cdot\left(E-\hat{c}_{1}(\tau+\Delta)\right) \\
& =R^{*}(\tau+\Delta, p(\tau+\Delta)) \cdot \frac{p(\tau+\Delta) L^{0}}{1-\tau-\Delta} \\
& >R^{*}(\tau, p(\tau)) \cdot \frac{p(\tau) L^{0}}{1-\tau} \\
& =R^{*}(\tau, p(\tau)) \cdot\left(E-\hat{c}_{1}(\tau)\right)=\hat{c}_{2}(\tau) .
\end{aligned}
$$

Since $\hat{c}_{2}(\tau+\Delta)=c_{2}\left(R^{*}(\tau+\Delta, p(\tau+\Delta))\right)$ and $\hat{c}_{2}(\tau)=c_{2}\left(R^{*}(\tau, p(\tau))\right)$, by Lemma A.1, (A.32) implies that $R^{*}(\tau, p(\tau))<R^{*}(\tau+\Delta, p(\tau+\Delta))$, contrary to (A.31). The assumption that $R^{*}(\tau, p(\tau))$ fails to be increasing in $\tau$ has thus led to a contradiction and must be false. By Lemma A.1, it follows that $\hat{c}_{2}(\tau)$ must also be increasing in $\tau$. The first statement of Proposition 4.5 is thereby proved.

Proposition 4.4 follows because, with $R^{*}(\tau, p(\tau))$ is increasing in $\tau$, all generations $t \geq 1$ are made better off by the change, and with $\hat{c}_{2}(\tau)$ increasing in $\tau$, generation 0 is also made better off.

The second statement of Proposition 4.5 follows from the observation that, as $R^{*}(\tau, p(\tau))$ is increasing in $\tau$, by Lemma A.1 and the curvature condition (4.23), $\hat{c}_{1}(\tau)$ is nondecreasing, and $E-\hat{c}_{1}(\tau)$ is nonincreasing in $\tau$. Spending on land, $p(\tau) L^{0}=(1-\tau)\left(E-\hat{c}_{1}(\tau)\right)$, is therefore decreasing in $\tau$. Thus $p(\tau)$ goes down and $r(p(\tau))$ goes up as $\tau$ is increased.

Proof of Proposition 5.1. Since $L^{0}$ and $M^{0}$ are strictly positive, any stationary monetary equilibrium satisfies $L^{t}>0$ and $M^{t}>0$ for all $t$. In every period, therefore, the rates of return on land and money must be the same, i.e., the prices $p_{t}, q_{t}, t=1,2, \ldots$ must satisfy the equation

$$
\frac{q_{t+1}}{q_{t}}=\frac{a+p_{t+1}(1-\pi)}{p_{t}}
$$

for all $t$. With stationarity, this equation takes the form

$$
1=\frac{a}{p}+1-\pi
$$

or $p=\frac{a}{\pi}$, as claimed in the proposition. The equilibrium net real rate of return on land, $\frac{a}{p}-\pi$ must therefore be equal to zero. With this rate of return, utility 
maximization requires that, for any $t \geq 1,\left(c_{1}^{t}, c_{2}^{t}\right)$ must maximize $u\left(c_{1}\right)+v\left(c_{2}\right)$ under the constraint $c_{1}+c_{2}=E$. Moreover, the first-period savings $E-c_{1}$ must be equal to the sum $p L^{t}+q M^{t}=p L^{0}+q M^{0}$ of the values of land and money held. Since $p=\frac{a}{\pi}$, it follows that $q=\left[E-c_{1}-\frac{a}{\pi} L^{0}\right] / M^{0}$, as claimed in the proposition.

For a monetary equilibrium, $q$ must be positive, i.e. we must have $E-c_{1}>$ $\frac{a}{\pi} L^{0}$. I claim that this is not possible if $\frac{a}{p^{*}}-\pi \geq 0$, where, for simplicity, I have dropped the arguments from $p^{*}=p^{*}\left(E, a, \pi, L^{0}\right)$. To prove this claim, suppose that we have $E-c_{1}>\frac{a}{\pi} L^{0}$ and $\frac{a}{p^{*}}-\pi \geq 0$. Then, trivially, $\frac{a}{\pi} \geq p^{*}$ and therefore

$$
r\left(\frac{a}{\pi}\right) \leq r\left(p^{*}\right) \text { and } r\left(\frac{a}{\pi}\right) \cdot \frac{a}{\pi} \geq r\left(p^{*}\right) \cdot p^{*}
$$

By (A.34), $r\left(\frac{a}{\pi}\right)=1$. By (A.35) and the constraint $c_{1}+c_{2}=E$, it follows that

$$
c_{2}=E-c_{1}>\frac{a}{\pi} L^{0}=r\left(\frac{a}{\pi}\right) \cdot \frac{a}{\pi} \cdot L^{0} \geq r\left(p^{*}\right) \cdot p^{*} \cdot L^{0} .
$$

By the budget constraints in $(2.2), r\left(p^{*}\right) \cdot p^{*} \cdot L^{0}=c_{2}\left(r\left(p^{*}\right)\right)$, where, for any $r, c_{2}(r)$ maximizes $u\left(E-\frac{1}{r} c_{2}\right)+v\left(c_{2}\right)$. Thus, (A.36) implies $c_{2}>c_{2}\left(r\left(p^{*}\right)\right)$. However, one easily verifies that the function $c_{2}(\cdot)$ must be nondecreasing. Since $c_{2}=c_{2}(1)$ and, by (A.34) and (A.35), $1=r\left(\frac{a}{\pi}\right) \leq r\left(p^{*}\right)$, it follows $c_{2} \leq c_{2}\left(r\left(p^{*}\right)\right)$. The assumption that we can have $E-c_{1}>\frac{a}{\pi} L^{0}$ and $\frac{a}{p^{*}}-\pi \geq 0$ has thus led to a contradiction and must be false.

Conversely, suppose that $\frac{a}{p^{*}}-\pi<0$, where again $p^{*}$ is shorthand for $p^{*}\left(E, a, \pi, L^{0}\right)$. Then $\frac{a}{\pi}<p^{*}$ and therefore

$$
r\left(\frac{a}{\pi}\right)>r\left(p^{*}\right) \text { and } r\left(\frac{a}{\pi}\right) \cdot \frac{a}{\pi}<r\left(p^{*}\right) \cdot p^{*} .
$$

Using (A.34), (A.37) and the constraint $c_{1}+c_{2}=E$, one now obtains

$$
E-c_{1}=c_{2}>c_{2}\left(r\left(p^{*}\right)\right)=r\left(p^{*}\right) \cdot p^{*} \cdot L^{0}>r\left(\frac{a}{\pi}\right) \cdot \frac{a}{\pi} \cdot L^{0}=\frac{a}{\pi} \cdot L^{0},
$$

so $q=\left[E-c_{1}-\frac{a}{\pi} L^{0}\right] / M^{0}$ is strictly positive. One easily verifies that the specified price sequence and allocation is indeed a stationary monetary equilibrium.

To see that this equilibrium Pareto-dominates the stationary equilibrium under laissez-faire without money, it suffices to observe that second-period consumption is higher - so generation 0 is better off - and the equilibrium rate of return on assets is also higher - so later generations are also better off.

Pareto efficiency follows by the arguments of Okuno and Zilcha (1980) for the case when the interest rate is equal to the growth rate of the economy.

\section{B A Model with Real Capital Bearing Risky Re- turns}

In this appendix, I extend the model of Sections 2 and 3 to allow for real capital, a produced non-durable asset with risky returns. In any period $t$, a member of 
generation $t$ can use some of the endowment $E$ to make a real investment $I^{t}$, which earns a random return $\tilde{\theta}_{t+1} I^{t}$ in period $t+1$. I assume that the random variables $\tilde{\theta}_{t+1}, t=1,2, \ldots$, are independent and identically distributed, with

$$
E \tilde{\theta}_{t+1}>1 \text { and } \operatorname{Pr}\left\{\tilde{\theta}^{t+1}=0\right\}>0 .
$$

To keep the exposition simple, I assume that utility functions are logarithmic, so in the absence of taxes and transfers generation $t \geq 1$ now chooses a plan $\left(c_{1}^{t}, \tilde{c}_{2}^{t}, L^{t}, I^{t}\right)$ to maximize

$$
\ln \left(c_{1}^{t}\right)+E \ln \left(\tilde{c}_{2}^{t}\right)
$$

under the constraints

$$
c_{1}^{t}=E-I^{t}-p_{t} L^{t}
$$

and

$$
\tilde{c}_{2}^{t}=\tilde{\theta}_{t+1} I^{t}+r\left(p_{t+1}\right) p_{t+1} L^{t},
$$

where, as before, $r\left(p_{t+1}\right)=a+(1-\pi) p_{t+1}$. A stationary equilibrium involves a land price sequence $\left\{p_{t}\right\}_{t=1}^{\infty}$, with $p_{t}=p$ for all $t$, for some $p$, and an allocation $\left\{\tilde{c}_{2}^{t-1}, c_{1}^{t}, L^{t}, I^{t}\right\}_{t=1}^{\infty}$ such that the plans $\left(c_{1}^{t}, \tilde{c}_{2}^{t}, L^{t}, I^{t}\right)$ solve the different generations' maximization problems and, moreover, markets clear in all periods.

Using (B.3) and (B.4), one can rewrite (B.2) as

$$
\ln \left(E-I^{t}-p L^{t}\right)+E \ln \left(\tilde{\theta}_{t+1} I^{t}+r(p) p L^{t}\right) .
$$

Given that the random variables $\tilde{\theta}_{t+1}, t=1,2, \ldots$, are independent and identically distributed, with $p_{t}=p$ for all $t$, the problem of choosing $I^{t}$ and $L^{t}$ to maximize (B.5) has a unique solution $(I, L)$. Moreover, by standard calculations this solution takes the form

$$
I=\varphi(r(p)) \cdot \frac{E}{2}, L=\frac{1}{p} \psi(r(p)) \cdot \frac{E}{2},
$$

where

$$
\varphi(r(p))+\psi(r(p))=1
$$

for all $p$. The associated values for consumption plans are $c_{1}=\frac{E}{2}$ and $\tilde{c}_{2}=$ $\left[\tilde{\theta}_{t+1} \varphi(r(p))+r(p) \psi(r(p))\right] \cdot E .^{24}$

Lemma B.1 Under the given assumptions about utility functions and about the random returns on real investments, for any $r>0$, the functions $\varphi$ and $\psi$ in (B.6) satisfy

$$
\begin{gathered}
\varphi(r)>0 \text { if and only if } r<E \tilde{\theta}_{t+1} . \\
\psi(r)>0 \text { for all } r>0,
\end{gathered}
$$

with $\psi(r)=1$ for $r \geq E \tilde{\theta}_{t+1}$. At any $r \in\left(0, E \tilde{\theta}_{t+1}\right), \varphi(r)$ is decreasing and $\psi(r)$ is increasing in $r$.

\footnotetext{
${ }^{24}$ This is where logarithmic utility helps. In the general case of constant relative risk aversion, $u^{\prime}(c)=v^{\prime}(c)=c^{\gamma-1}, \gamma<1$, the optimal $c_{1}$ is increasing in $r(p)$ if $\gamma<0$ and decreasing in $r(p)$ if $\gamma \in(0,1)$. For $\gamma \in(0,1)$, all results in the text go through without change. For $\gamma<0$, the uniqueness and monotonicity claims in Proposition B.2 might not go through, but the limit (B.10) remains valid.
} 
Proof. By (B.6) and (B.7), the first term in (B.5) is equal to $\ln \left(\frac{E}{2}\right)$ and the second term equal to

$$
E \ln \left(\tilde{\theta}_{t+1} \varphi+r(p) \psi\right)+\ln \left(\frac{E}{2}\right) .
$$

The pair $(\varphi(r(p)), \psi(r(p)))$ must maximize (B.8) under the constraint (B.7). By the strict concavity of the logarithm, it follows that $r(p) \geq E \tilde{\theta}_{t+1}$ implies $\varphi(r(p))=0$ and $\psi(r(p))=1$.

If $r(p)<E \tilde{\theta}_{t+1}$, then, at the point $\varphi=0, \psi=1$, the derivatives of (B.8) with respect to $\varphi$ and $\psi$ are

$$
E \frac{\tilde{\theta}_{t+1}}{\tilde{\theta}_{t+1} \varphi+r(p) \psi}=E \frac{\tilde{\theta}_{t+1}}{r(p)}>1 \text { and } E \frac{r(p)}{\tilde{\theta}_{t+1} \varphi+r(p) \psi}=1,
$$

so an increase in $\varphi$ combined with an equal-sized decrease in $\psi$ raises (B.8), proving that the pair $(\varphi, \psi)=(0,1)$ does not maximize (B.8) subject to (B.7) and that, therefore, $\varphi(r(p))>0$ and $\psi(r(p))<1$ if $r(p) \in\left(0, E \tilde{\theta}_{t+1}\right)$.

Maximization of (B.8) also requires $\psi(r(p))>0$ whenever $r(p)>0$; if we had $r(p)>0$ and $\psi(r(p))=0$, then, because $\operatorname{Pr}\left\{\tilde{\theta}^{t+1}=0\right\}>0$, the derivative of (B.8) with respect to $\psi$ would be unboundedly positive.

At any $r(p) \in\left(0, E \tilde{\theta}_{t+1}\right)$, we thus have $\varphi(r(p))>0$ and $\psi(r(p))>0$, so the pair $(\varphi(r(p)), \psi(r(p)))$ must satisfy the first-order condition for an interior maximum,

$$
E \frac{\tilde{\theta}_{t+1}-r(p)}{\tilde{\theta}_{t+1} \varphi+r(p) \psi}=0 .
$$

Because the logarithmic function exhibits decreasing absolute risk aversion, by standard arguments, (B.9) implies that $\varphi(r)$ is decreasing and $\psi(r)$ is increasing in $r$ at $r=r(p) \in\left(0, E \tilde{\theta}_{t+1}\right)$.

Proposition B.2 For given $E, a, \pi, L^{0}$, the model with real investments and with logarithmic utility has a unique stationary equilibrium. The equilibrium land price is increasing in the endowment $E$, with

$$
\lim _{E \rightarrow \infty} p^{*}\left(E, a, \pi, L^{0}\right)=\infty .
$$

If $E$ is sufficiently large, the stationary-equilibrium net real rate of return on land,

$$
r\left(p^{*}\left(E, \pi, L^{0}\right)\right)-1=\frac{a}{p^{*}\left(E, a, \pi, L^{0}\right)}-\pi,
$$

is negative, and the stationary equilibrium is not weakly efficient.

Proof. Market clearing requires that the (stationary) demand for land $L$ be equal to the available stock $L^{0}$. By (B.6), this condition holds if and only if the equilibrium land price satisfies the equation

$$
p=\frac{1}{L^{0}} \cdot \psi(r(p)) \cdot \frac{E}{2} .
$$


If $p$ is close to zero, $r(p)$ is very large so the right-hand side of (B.12) is $\frac{E}{2 L^{0}}>p$. If $p$ is very large, the right-hand side of (B.12) is no larger than $\frac{E}{2 L^{0}}$, which is less than $p$. Existence of a market-clearing land price follows by the intermediatevalue theorem. Uniqueness follows by the monotonicity of the difference $p-\frac{1}{L^{0}}$. $\psi(r(p)) \cdot \frac{E}{2}$ in $p$. Monotonicity of the equilibrium land price in $E$ also follows by the monotonicity of the difference $p-\frac{1}{L^{0}} \cdot \psi(r(p)) \cdot \frac{E}{2}$. Finally, (B.10) follows from the observation that, by definition, $r(p)>1-\pi$ and therefore $\psi(r(p))>\psi(1-\pi)$ for all $p$. Thus

$$
p^{*}\left(E, a, \pi, L^{0}\right) \geq \frac{1}{L^{0}} \cdot \psi(1-\pi) \cdot \frac{E}{2}
$$

for all $\pi$, and (B.10) follows because, by Lemma B.1, $\psi(1-\pi)>0$.

The last statement of the proposition follows by the same argument as in Propositions 3.2 and 3.3 .

Remark B.3 In any stationary equilibrium, whether efficient or not, the expected rate of return on real investment exceeds the real growth rate, i.e., E$\tilde{\theta}_{t+1}>$ 1 for all $t$.

Proposition B.4 Suppose that $E$ is large enough so that the stationary-equilibrium net real rate of return on land (B.11) under laissez-faire is negative, i.e., $p^{*}\left(E, a, \pi, L^{0}\right)>\frac{a}{\pi}$. Then, for

$$
T=S=\frac{E}{2}(1-\varphi(1))-\frac{a}{\pi} L^{0},
$$

there exists a Pareto-dominating stationary equilibrium of the model with real investments and with logarithmic utility, with a lump-sum tax $T$ in the first period of people's lives and a lump-sum transfer $S$ in the second period, such that the stationary equilibrium land price is $\hat{p}=\frac{a}{\pi}$, with $r(\hat{p})=1$, and the stationary-equilibrium real investment is $\hat{I}=\varphi(1) \frac{E}{2}$.

Proof. Given $T, S, \hat{p}$, and $r(\hat{p})=1$, the problem of any generation $t \geq 1$ is to maximize (2.2) under the constraints

$$
c_{1}^{t}=E-T-I^{t}-p L^{t}
$$

and

$$
\tilde{c}_{2}^{t}=S+\tilde{\theta}_{t+1} I^{t}+p L^{t} .
$$

This is equivalent to the problem of maximizing (2.2) under the consolidated constraint

$$
\begin{aligned}
\tilde{c}_{2}^{t} & =S+\tilde{\theta}_{t+1} I^{t}+E-T-I^{t}-c_{1} \\
& =\left(\tilde{\theta}_{t+1}-1\right) I^{t}+E-c_{1} .
\end{aligned}
$$

The consolidated constraint is exactly the same as in a situation without the lump-sum tax and transfer, but with the price $\hat{p}$ and rate of return on land $r(\hat{p})=$ 
1. The solution to the problem of maximizing (2.2) subject to $(B .16)$ is therefore also the same, namely $c_{1}^{t}=\frac{E}{2}, I^{t}=\varphi(1) \cdot \frac{E}{2}$, and $\tilde{c}_{2}^{t}=\left(\tilde{\theta}_{t+1}-1\right) \varphi(1) \cdot \frac{E}{2}+\frac{E}{2}$. By (B.14) and (B.13), the demand for land is

$$
\frac{1}{p} \cdot\left[\frac{E}{2}-T-\varphi(1) \cdot \frac{E}{2}\right]=\frac{1}{p} \frac{a}{\pi} L^{0},
$$

which is equal to the stock of land $L^{0}$ if and only if $p=\frac{a}{\pi}$. Pareto dominance of the equilibrium with lump-sum taxes and transfers over the laissez-faire equilibrium follows because the rate of return on land is higher and second-period expected utility is also higher.

Remark B.5 Relative to the stationary equilibrium with lump-sum taxes and transfers in Proposition B.4, the laissez-faire equilibrium exhibits an overinvestment in real capital.

\section{References}

[1] Abel, A.B., N.G. Mankiw, L.H. Summers, R.J. Zeckhauser (1989), Assessing Dynamic Efficiency, Review of Economic Studies 56 (1), 1-19.

[2] Allais, M. (1947), Économie et interêt, Imprimerie Nationale, Paris.

[3] Blanchard, O. (2019), Public Debt and Low Interest Rates, American Economic Review 109, 1197-1229.

[4] Breyer, F. (1989), On the Intergenerational Pareto Efficiency of Pay-asyou-go Financed Pension Systems, Journal of Institutional and Theoretical Economics (JITE) 145 (4), 643-658.

[5] Breyer, F., and M. Straub (1993), Welfare Effects of Unfunded Pension Systems when Labor Supply Is Endogenous, Journal of Public Economics 50 (1), 77-91.

[6] Diamond, D.W, and P.H. Dybvig (1983), Bank Runs, Deposit Insurance, and Liquidity, Journal of Political Economy 91 (3), 401-419.

[7] Diamond, P.A. (1965), National Debt in a Neoclassical Growth Model, American Economic Review 55, 1126-1150.

[8] Feldstein, M. (1977), The Surprising Incidence of a Tax on Pure Rent: A New Answer to an Old Question, Journal of Political Economy 85 (2), 349-360.

[9] Fisher, I. (1933), The Debt-Deflation Theory of Great Depressions, Econometrica. 1 (4), 337-357. 
[10] Grandmont, J.-M., and G. Laroque (1973), Money in the Pure Consumption Loan Model, Journal of Economic Theory 6, 382-395.

[11] Hellwig, M.F. (2020), Property Taxes and Dynamic Inefficiency: A Correction of a "Correction", Economics Letters 197, https://doi.org/10.1016/j.econlet.2020.109603.

[12] Hellwig, M.F. (2021), Safe Assets, Risky Assets, and Dynamic Inefficiency in Overlapping-Generations Economies, Max Planck Institute for Research on Collective Goods, Discussion Paper 2021/10.

[13] Homburg, S. (1987), Theorie der Alterssicherung (Theory of Old-Age Provision), Springer, Berlin et al.

[14] Homburg, S. (1990), The Efficiency of Unfunded Pension Schemes, Journal of Institutional and Theoretical Economics (JITE) 146 (4), 640-647.

[15] Homburg, S. (1991), Interest and Growth in an Economy with Land, Canadian Economic Journal 24, 450-459.

[16] Homburg, S. (2014a), Overaccumulation, Public Debt and the Importance of Land, German Economic Review 15, 411-435.

[17] Homburg, S. (2014b), Property Taxes and Dynamic Efficiency: A Correction, Economics Letters 123, 327-328.

[18] Kim, K.-S., and J. Lee (1997), Reexamination of Dynamic Efficiency with Taxation on Land, Economics Letters 57, 169-175.

[19] Malinvaud, E. (1987), The Overlapping Generations Model in 1947, Journal of Economic Literature 25(1), 103-105.

[20] Okuno, M., and I. Zilcha (1980), On the Efficiency of a Competitive Equilibrium in Infinite Horizon Monetary Economies, Review of Economic Studies 47 (4), $797-807$.

[21] Rachel, L., and L.H. Summers (2019), On Falling Neutral Rates, Fiscal Policy, and the Risk of Secular Stagnation, Brookings Papers on Economic Activity, Spring 2019, 1-66.

[22] Rhee, C. (1991), Dynamic Inefficiency in an Economy with Land, Review of Economic Studies 58, 791-797.

[23] Samuelson, P.A. (1958), An Exact Consumption-Loan Model of Interest with or without the Social Contrivance of Money, Journal of Political Economy 66, 467-482.

[24] Santos, M.S., and M. Woodford (1997), Rational Asset Pricing Bubbles, Econometrica 65, 19-57. 
[25] Sinn, H.-W. (2020), Staatsverschuldung und dynamische Ineffizienz: Warum der Münchhausen-Trick nicht funktioniert (Government Debt and Dynamic Inefficiency: Why the Münchhausen Trick does not Work), Wirtschaftsdienst 100, 572-577.

[26] Summers, L.H. (2014), U.S. Economic Prospects: Secular Stagnation, Hysteresis, and the Zero Lower Bound, Business Economics 49 (2), National Association for Business Economics.

[27] Tirole, J. (1985), Asset Bubbles and Overlapping Generations, Econometrica 53, 1071-1100.

[28] von Mises, L. (1924/1953), The Theory of Money and Credit, Yale University Press, New Haven, Conn. 1953, English translation of: Die Theorie des Geldes und der Umlaufsmittel, 2nd Edition, Duncker\&Humblot, Leipzig, 1924.

[29] von Weizsäcker, C.C. (2010), Das Janusgesicht der Staatsschulden (The Janus Face of Public Debt), Frankfurter Allgemeine Zeitung, June 5, 2010.

[30] von Weizsäcker, C.C. (2014), Public Debt and Price Stability, German Economic Review 15, 42-61.

[31] von Weizsäcker, C.C., and H. Krämer (2019), Sparen und Investieren im 21. Jahrhundert: Die große Divergenz (Saving and Investment in the $21^{\text {st }}$ Century: The Great Divergence), SpringerGabler, Wiesbaden. 